\title{
A Distributional Analysis of Uni-and Multidimensional Poverty and Inequalities in Ethiopia
}

\author{
Mekonnen Bersisa ${ }^{1} \cdot$ Almas Heshmati $^{2}$ D
}

Accepted: 1 January 2021 / Published online: 2 February 2021

(c) The Author(s) 2021

\begin{abstract}
This study analyzes uni-and multidimensional poverty and inequalities in rural and small towns in Ethiopia. Unlike the unidimensional measure, the multidimensional measure of poverty shows all the channels through which poverty may manifest itself; it also shows the extent of deprivation. The analysis uses 6 dimensions with 14 indicators to construct a multidimensional index of poverty and inequalities using Ethiopian Households' Socioeconomic Survey dataset. The study also uses multiple correspondence analyses for determining relative weights in computing a multidimensional index and conducts a stochastic dominance analysis of distribution of poverty for different population segments. The paper sheds light on the degree of inequalities in consumption expenditure and multidimensional deprivations. In addition, it also compares the degree of poverty using the conventional measure of poverty and the multidimensional approach. It also examines the determinants of household poverty status using both unidimensional and multidimensional measures using the logit model. The results show that the intensity, severity, and depth of poverty varies substantially across the 2 measures. The unidimensional measure of poverty shows that 36 percent of the households were poor as compared to 46 percent multidimensionally poor households. Moreover, demographic, regional, and household heads' characteristics also affect households' poverty status.
\end{abstract}

Keywords Multidimensional poverty $\cdot$ Inequality $\cdot$ Deprivation $\cdot$ Factor analysis · Stochastic dominance $\cdot$ Ethiopia

JEL Classification C25 $\cdot \mathrm{C} 31 \cdot \mathrm{C} 43 \cdot \mathrm{D} 31 \cdot \mathrm{I} 32$

The authors are grateful to two anonymous reviewers and an editor of the journal for their comments and suggestions on an earlier version of this manuscript.

Almas Heshmati

almas.heshmati@gmail.com

Mekonnen Bersisa

mbersisa@gmail.com

1 Department of Economics, Ambo University Woliso Campus, Waliso, Ethiopia

2 Jönköping International Business School, Jönköping University, Room B5017, P.O. Box 1026, 55111 Jönköping, Sweden 


\section{Introduction}

Measuring and analyzing well-being or poverty has involved considerable efforts by academics, policymakers, and social planners. However, no consensus about its measurement has been reached so far despite the issue having been under scrutiny for a long time. Contemporary works admit that it is a multidimensional phenomenon and measurements that account for various aspects of poverty have got prominence in literature. It is found that conventional wisdom about measuring poverty is far removed from households' realities. This approach defines poverty as scarcity of economic resources or incomes to meet minimum basic needs for a decent life. It shows monetary values of the materials necessary for meeting basic needs in terms of consumption expenditure or income (Gustafsson 1995; Townsend 1970). Thus, poverty alleviation policies have focused on providing the poor with means to ends. However, a resource-based measurement of poverty has been criticized as it fails to show the channels through which poverty manifests itself. It also does not unambiguously reveal the true picture of social ills, capabilities, functioning, and income distribution. The other dimensions of deprivations are the disparities among households with different achievements. This aspect has attracted research attention which uses several measures of income inequalities. But less attention has been paid to multidimensional inequalities.

As explained by Sen (1976), 2 inter-related but pertinent problems are encountered when measuring poverty. The first is identifying the poor among the total population. This involves selecting a criterion for determining the poverty line and identifying the poor from the non-poor, and the second is aggregating the features of poor people into overall indicators. Sen's criticism about the existing unidimensional indices of well-being/poverty and his suggestion for an axiomatic approach for measuring poverty instigated waves of research work in the area. Countless efforts were made to develop multidimensional indices (Alkire and Foster 2007, 2011; Alkire and Santos 2010; Bourguignon and Chakravarty 2003; Kakwani and Silver 2008; Tsui 2002).

A good indicator of poverty should go beyond the mere expenditure or income required to attain minimum basic needs and also show deprivations and capabilities (Sen 1976, 1990, 1999). A multidimensional approach to measuring poverty thus plays a prominent role in tracking and showing all channels through which poverty may be manifested. Recently, empirical work is emerging in the study of poverty using this approach (Chakravarty et al. 1998; Khan et al. 2014; Maasoumi and Xu 2015; Nussbaum 2003).

Poverty and inequalities are critical for developing countries where there is pervasive, deep-rooted, and multifaceted poverty and the extent of inequalities is intolerable. Ethiopia, with great diversity in terms of landscape, climate, ethnicity, and livelihood patterns, is a developing country which has had abject and persistent poverty over a long period. The country is the second most populous in Africa with a population of about 99 million and a population growth rate of 2.5 percent. ${ }^{1}$ As per HDR (2015), Ethiopia was ranked 174th out of 188 countries for which the Human Development Index (HDI) was computed. Components of the 2014 HDI for the country showed that its HDI was 0.442 ; life expectancy at birth was 64.1 years; mean years of schooling was 2.4 years; and GDP per capita was $\$ 590$ using the Atlas method which is substantially lower than the regional average. Table 1 shows trends and growth in HDI for Ethiopia over the last 15 years.

${ }_{1}^{1}$ http://www.worldbank.org/en/country/ethiopia/overview accessed on November 30, 2016. 
Table 1 Human Development Index (HDI) for Ethiopia (200014) Source: Compiled from $\operatorname{HDR}(2013,2014$, and 2015)

\begin{tabular}{lll}
\hline Year & HDI & $\begin{array}{l}\text { Growth rate } \\
\text { (percentage) }\end{array}$ \\
\hline 2000 & 0.284 & - \\
2005 & 0.347 & 22.18 \\
2010 & 0.412 & 18.73 \\
2011 & 0.423 & 2.67 \\
2012 & 0.429 & 1.42 \\
2013 & 0.436 & 1.63 \\
2014 & 0.442 & 1.38 \\
\hline
\end{tabular}

As we can see in Table 1 Ethiopia has shown promising improvements in its HDI. However, it is important to realize that the growth rate of its HDI shows a tendency of increasing at a decreasing rate, especially in later years. Notwithstanding these facts, Ethiopia has been registering impressive economic growth for the last decade averaging at about 11 percent. For attaining the overall development goals, the Government of Ethiopia launched an ambitious development plan, the Growth and Transformation Plan (GTP) in 2011 which had a target of achieving lower middle-income status by 2025. In its first five years (2011-15) GTP-I targeted attaining Millennium Development Goals (MDGs) by 2015 among other national goals. The second five years' growth and transformation plan (GTP-II) (2016-20) focused on modernization of agricultural development, industrialization, structural transformation, and developing foreign trade (FDRE 2011, 2016).

However, regardless of a remarkable economic growth rate the situation might lead to further questions on fairness or equity and the welfare implications of economic growth. Further, there is also a long-standing controversy on whether economic growth actually means improving the citizens' welfare. The effects of growth on the poor include welfare effects of improvements in the non-income dimension (Deaton 2005). As Sen (1999: 14) puts it, 'Economic growth cannot be sensibly treated as an end in itself. Development has to be more concerned with enhancing the lives people lead and the freedoms they enjoy.' Faster economic growth does not necessarily get translated into poverty reduction. Therefore, a scrutiny of the poverty situation in Ethiopia regardless of its sustained reported economic growth is needed.

Scholars agree on defining poverty as a 'pronounced deprivation of well-being.' However, the question of how to measure this deprivation remains unaddressed. Conventionally, it is considered as material deprivation and thus low income or consumption is used as an indicator of deprivation (Bossert et al. 2013). A low level of income or consumption results in high levels of human poverty. Measuring poverty using this method has been subject to criticism (Bourguignon and Chakravarty 2003; Kakwani and Silver 2008; Sen 1979, 1985; Tsui 2002). Moreover, income and human poverty are accompanied by many social deprivations. The broadest approach for measuring poverty (well-being) gives due emphasis to individuals' capabilities to function in a society rather than having a mere command over commodities. To encompass these multifaceted deprivations in measuring well-being it is inevitable that we have to look beyond income deprivation and also measure social exclusion (Chakravarty and D'Ambrosio 2006).

There is considerable literature on sub-Saharan African (SSA) countries, including Ethiopia which measures poverty using the unidimensional approach. However, limited studies have been conducted in the country using a multidimensional index (Ambel et al. 2015; Bersisa and Heshmati 2016; Brück and Sindu 2013; Woldehanna 2014). 
Berisso (2016) presents a detailed analysis of the determinants of consumption expenditure and dynamics of poverty in urban Ethiopia using panel data. His study indicates the persistence of poverty. However, existing literature in this area is not rigorous enough to serve as an input for policy interventions. Using a fixed weighting scheme, overlapping approaches to an analysis of multidimensional poverty, and exclusion of the extent of multidimensional inequalities are some of the gaps observed in existing literature.

The purpose of this study is examining the determinants and extent of poverty in rural and small towns in Ethiopia in greater detail. It also examines the extent of deprivation of households in a multidimensional set-up. One major contribution of this study is the use of estimated relative weights for attributes included in the multidimensional index. It also examines multidimensional inequalities in Ethiopia. Besides, energy use is added as an explicit indicator of well-being to account for possible externalities of energy use (for example, its health and environmental effects). Further, individual heterogeneity is taken care of by doing a disaggregated analysis of poverty and inequalities for different sub-groups. This research also examines the contribution of each dimension to multidimensional poverty. It conducts a stochastic dominance analysis of distribution in the conventional and multidimensional measurements of poverty. Finally, it examines the determinants of income and multidimensional poverty.

The rest of this paper is organized as follows. Section 2 presents a review of previous works on basic concepts of poverty, measuring poverty/well-being and its distribution, a dominance analysis, and weight estimations. Section 3 presents the theoretical foundations and models for both unidimensional and multidimensional poverty analyses. Section 4 discusses the results and the final section gives the conclusion.

\section{Issues in Poverty and Inequality Measurement and Analysis}

An in-depth analysis of multidimensional poverty has been long due for various reasons. The issue has been at the forefront of the economic and policy agenda since the 1970s with various degrees of emphasis. Over the years, the concept has evolved a dynamic nature. It has been the central focus of policymakers and academics and has been a subject of political debate. Similarly, studies on inequalities in different forms: inequalities in employment opportunities, education, safety and security, power, and economic inequalities have become the central focus of development endeavors (Ruiz-Castillo 2015). While the poverty measure focuses on the welfare of the poor per se, the measure of inequality provides for the welfare of the entire society under consideration. The relative distribution of deprivations is as important as absolute deprivation (Davidson and Duclos 2000; Maasoumi 1986; Tsui 1999). All this has created an overwhelming interest in the various dimensions of poverty and broadened the measurement of poverty and inequalities. However, the most debatable issue at this junction is the conceptual framing of poverty and inequalities and their measurement. As Sen (1976) showed, 2 distinct problems are encountered in measuring poverty. The first problem is identifying the poor among the total population, while the second is constructing an index of poverty from the information that we have about the poor.

In early writings, poverty alleviation or targeting was defined as providing or endowing the poor with a means to ends or with the ends directly. The focus in these writings was using income or expenditure as an indicator of well-being of individuals or households. This literature addressed the former problem by setting the minimum income or 
consumption expenditure required to meet a minimum standard. The latter constructed an index of poverty (headcount) by counting individuals whose income or expenditure fell short of this minimum requirement (poverty line). The headcount ratio merely shows the percentage of people below the poverty line. However, the headcount measure of poverty (H) has faced severe criticism as a response to which efforts have been made at developing various indices to circumvent its shortcomings.

Sen (1976) developed an index of poverty measurement using an axiomatic approach. This index of poverty measurement adjusts the headcount ratio to income gap and the Gini coefficient of distribution of income among the poor. On the other hand, Foster et al. (1984) developed a class of decomposable poverty measures that varied with a 'poverty aversion' parameter, resulting in the headcount ratio, the poverty gap index, and the squared poverty gap index for measuring the incidence, depth, and severity of poverty respectively. Though general, Atkinson (1987) established a common approach for evaluating poverty indices using the dominancy condition. Foster and Shorrocks (1991) introduced a sub-group consistent index of poverty measurement and Shorrocks (1995) extended Sen's index. ${ }^{2}$ In literature on poverty, considerable empirical work is available using these indices of poverty measurement (Dercon and Krishnan 2000; Dercon et al. 2005; Hagenaars and De Vos 1988; Kakwani 1993; Ravallion 1996; Ravallion and Huppi 1991).

The focus on defining and measuring poverty was challenged by Sen's (1976) seminal work. Following his footsteps tremendous scholarly efforts were devoted to the subject and several indices of poverty measurement were developed. Sen's groundbreaking work in 1999 on the capability approaches for measuring well-being created an impetus for poverty measurement. As a result, over the last two decades, interest in multidimensional poverty measures has been growing steadily (especially works by Tsui 2002 and Bourguignon and Chakravarty 2003); this has also motivated the development of several approaches for measuring or analyzing poverty beyond the unidimensional unit by considering its multidimensional aspects. The Oxford Poverty and Human Development Initiatives (OPHI) in collaboration with the United Nations Development Program's Human Development Report Office developed consistent and broad metrics for an international comparison among countries using multidimensional poverty in 2009-2010.

The first round of the Multidimensional Poverty Index (MPI) was released in 2010 (Alkire and Santos 2010). This multidimensional measure has merits as compared to the conventional measure of poverty with income cut-off per day (US\$1.25). Many researchers have shown that the 2 methods complement each other in measuring poverty. While MPI identifies those who actually fail to meet the accepted conventions of minimum needs or functioning, the latter measures poverty from the angle of the income necessary for meeting certain basic needs. There is well-established literature on the poverty measure in its multidimensional aspect (Alkire and Foster 2011; Alkire and Santos 2014; Atkinson 2003; Bourguignon and Chakravarty 2003; Chakravarty et al. 1998; Deutsch and Silber 2005; Khan et al. 2014; Maasoumi and Xu 2015; Tsui 2002; Whelan et al. 2014).

Countless studies on poverty, inequalities, and well-being have been published using multidimensional poverty measures in different parts of the world (Davidson and Duclos 2000; Deutsch and Silber 2005; Maasoumi 1986; Rogan 2016; Tsui 1999). For instance, Deutsch and Silber (2005) did a detailed analysis of multidimensional poverty using 4 different approaches: the fuzzy set theory, information theory, efficiency analysis, and

${ }^{2}$ Details of a survey of the various poverty indices can be obtained from Hagenaars (1987). 
axiomatic deprivation of poverty analysis. Their results show that the four approaches used for an analysis of multidimensionl povery using Israel's Census data for 1995 provided consistent results on poverty. The study further shows that multidimensinal poverty had a non-linear relationship with age of the household head and family size.

Khan et al. (2014) investigated the incidence of multidimensional poverty in the Rawalpindi region of Pakistan considering three dimensions: education, health, and housing. They used 10 variables to construct MPI. Their findings showed an inconsistent declining trend of multidimensional poverty over time. This inconsistency was mainly attributed to observed fluctuations in deprivation levels in education, health, and housing in the region. They concluded that the multidimensional approach was better in showing the extent of poverty and its severity for different groups. Similarly, Housseima and Jaleleddine (2012) followed a multidimensional approach for analyzing poverty for east-central Tunisia. Their study determined relative weights for each attribute. Alkire and Santos (2014) used 3 datasets to rigorously analyze a multidimensional poverty index for developing countries.

One can find vast literature on poverty and inequality analyses using both conventional and multidimensional measures, yet due to poverty's dynamic nature and its being location-specific and policy relevant, it is important to conduct more research to foster policymaking and for broadening the academic and political dialogue in this area.

\section{Analytical Framework and Data}

\subsection{Data Sources and Selection of Variables}

This study used data obtained from various sources. Primarily, the study relied on data collected by the Central Statistical Agency of Ethiopia (CSA) and the World Bank (WB). It also used data from different sources to complement the main data source. Two waves of data from the Ethiopian Socioeconomic Survey (ESS) which is a collaborative project between CSA and the WB Living Standards Survey were used. The first wave of the data was collected in 2011 and the second in 2014 which was released in 2015. The survey is comprehensive and multi-topic so it can be flexibly used for welfare analyses using different attributes.

The first wave of the survey covered almost all the rural parts and small towns in the country. The purpose of the survey was sharing knowledge across countries, building capacity, and improving survey methodologies and technologies. The survey encompassed all regional states in the first round except capital Addis Ababa. Its primary focus was rural parts and small towns. Information was collected from 290 rural and 43 small town enumeration areas (EAs). ${ }^{3}$ This survey was the first round of a long-term project to collect panel data on rural and small-town households, their characteristics, welfare, and agricultural activities. As part of the first survey, information was collected from 3969 respondents in all the regions of the country.

In its second wave, the survey extended the sampling frame by including respondents from large urban areas including capital Addis Ababa. By doing this it tried to maintain country-wide representativeness of the data collected from the sample respondents. The

\footnotetext{
${ }^{3}$ The Central Statistical Agency of Ethiopia has developed a sampling frame. The smallest units from which households or individuals are selected to keep representativeness is known as an enumeration area (EA).
} 
second survey collected information from 5262 respondents of which 3776 were from the first wave. The 2 waves are expected to gradually form a panel data where the same households are observed over time. The panel attrition rate between the 2 existing waves is only 5 percent or the two-year panel success rate is about 95 percent which can be used for analyzing households' poverty status over time. Thus, our study used information from 3776 respondents in rural and small towns in Ethiopia who were covered in both rounds of the survey.

A multi-level questionnaire was used for collecting the data on household, community, and agricultural levels. A household was used as a primary sampling unit for the questionnaire and it was drawn from a population frame so as to be representative of the Ethiopian population, including all rural and small-town areas in the country except the 3 zones of Afar and 6 zones of Somalie region. A two-stage stratified sampling method was used for selecting the sampled households, where in the first stage primary sampling units were selected using the simple random sampling method from a sample of CSA enumeration areas. At this stage, probability proportion to size was used for determining the sample size for EAs. In the second stage of the sampling, households were randomly drawn from selected EAs for interviews. A detailed sampling procedure, sampling frame, sample size determination, and data quality can be obtained from the respective years of ERSS-basic information reports (CSA and WB 2013, 2015).

\subsection{Theoretical Framework for Poverty Analysis}

\subsubsection{A Unidimensional Analysis of Poverty}

There is vast literature on poverty analyses using a unidimensional approach. Regardless of its downsides, this literature conveys pertinent information to gauge the extent of poverty challenges; distributional comparisons; assessing public policies; and evaluating the impact of interventions (Ravallion 1994). For sound comparisons, we first explored the extent of poverty in rural and small urban areas in Ethiopia using the conventional unidimensional measures. The family of Foster, Greer, and Thorbecke (1984) poverty measure $\left(\mathrm{p}_{\alpha}\right)$ was computed using consumption expenditure. Here $\alpha$ was used for aggregating poverty to measure its incidence, depth, and severity for households. Suppose the per capita household $i$ 's consumption expenditure, denoted by $\mathrm{CE}_{\mathrm{i}}$, is arranged in an ascending order as: $\mathrm{CE}_{1} \leq \mathrm{CE}_{2} \leq \mathrm{CE}_{3} \leq \ldots \leq \mathrm{CE}_{\mathrm{r}} \leq \mathrm{Z} \leq \mathrm{CE}_{\mathrm{r}+1} \leq \ldots \leq \mathrm{CE}_{\mathrm{n}}$, where $Z$ stands for the poverty line, $n$ is the total population, and $r$ is the number of poor, then the consumption poverty index, $\mathrm{p}_{\alpha}$, is given by:

$$
P_{\alpha}=\frac{1}{n} \sum_{i=1}^{r}\left(\frac{Z-C E_{i}}{Z}\right)^{\alpha}
$$

Here the parameter $\alpha$ measures a policymaker's degree of aversion to inequalities among the poor. The higher the value of $\alpha$, the higher the weight attached to the poorest of the poor (Foster et al. 1984; Ravallion and Huppi 1991). Based on $\alpha(\alpha=0,1$ and 2) 3 indices of poverty measures can be constructed. For $\alpha=0$ the index is known as the headcount poverty index $\left(\mathrm{p}_{0}\right)$. It measures the incidence of poverty, that is, it shows the proportion of the population whose consumption expenditure per capita is below the poverty line. When $\alpha=1$, it gives the poverty gap index $\left(\mathrm{P}_{1}\right)$ which captures the depth of poverty. This provides information on how far households are from the poverty line. It shows the average distance 
separating the poor from the poverty line. Finally, when $\alpha=2$, one gets the squared poverty gap index $\left(\mathrm{P}_{2}\right)$, which captures the severity of poverty. It considers not only the distance separating the poor from the consumption poverty line, but also the inequalities among the poor.

However, determining the cut-off point in an analysis of poverty remains controversial. The definition of a poverty line depends on the purpose of the analysis. Poverty measurements and analyses are done to know the situation; to understand factors responsible for the situation; to design interventions; or for monitoring and evaluating policy interventions. Various poverty lines have been established in literature: the absolute poverty line, the relative poverty line, and the subjective poverty line. Detailed definitions and measurements of the poverty line are given in Duclos and Araara (2006) and Hagenaars and De Vos (1988). An absolute poverty line is defined as those people who fail to satisfy their minimum physical needs of food and non-food items. From this perspective, poverty is defined in terms of earning per day, cost of basic food and non-food items, and expenditure levels that meet food energy requirements (Anwar and Qureshi 2002). It is also common to define the poverty line relative to some overall distribution of sample statistics.

The most frequently used relative poverty line is some proportion of central tendencies' (mean or median) income or consumption expenditure (Foster et al. 2013; Muller 2006). Following literature, we used both absolute and relative poverty measures to see the extent of per capita poverty using consumption expenditure. We used consumption expenditure aggregates calculated as the sum of food and non-food expenditure for analyzing poverty in rural and small urban areas in Ethiopia. We used the consumption expenditure poverty line as the amount of money required to purchase $2100 \mathrm{kcal}$ per capita per day plus essential non-food items, as defined by the Ministry of Finance and Economic Development (MoFED 2008). Besides, the relative poverty line defined as 50 percent of mean expenditure was used for analyzing relative poverty in the study period.

\subsubsection{Effect of Household Size on Consumption Expenditure}

There is well-documented evidence in literature on the effect of family size and its composition on the status of a household. Household composition (gender and age of members) significantly affects expenditure per capita and the poverty level for the household. Computation of per capita income/expenditure using the number of members in a household produces an inaccurate measure of the standard of living. More importantly, it is difficult to compare the living standards of families having different sizes and compositions. Such a measure needs to be adjusted for the differences in the needs of people of different ages and sexes as well as the economies of scale advantage of larger families Buhmann et al. 1988; Deaton and Paxson 1998; Gronau 1988; Ray 2000). The essence of adult equivalence computation is explained by Glewwe (1991). It measures the relative income required to enable families of different sizes and compositions to enjoy the same standard of living.

The equivalence scale adjustment has tremendous implications for a poverty, inequality, and welfare analysis. It has attracted many adherents who have contributed to the development of several approaches for its computation. However, there is no generally accepted measure of equivalence scale to account for cost of children or the advantages of economies of scale in larger families (Buhmann et al. 1988; Deaton 2003; Deaton and Paxson 1998; Dercon and Krishnan 1998; Glewwe 1991; Gronau 1988; Ray 2000). The various approaches for computing equivalence scale can be categorized under 2 heads: objective and subjective approaches. The objective approach is generally based on observed behavior 
and uses econometric techniques. The subjective approach encompasses the parametric, questionnaire based, and nutrition or subsistence income-based approaches (Coulter et al. 1992). The nutrition based approach follows some steps to drive adult equivalence family size. It first determines the nutritional requirements of each household member. It then computes the money metric value of the nutritional requirements. Finally, it derives the equivalence scale adjustment for households of different sizes and compositions. Following this line, our study used the nutrition based approach for computing the equivalence scale. It converted family size to adult male equivalence to account for cost of children and the advantages of economies of scale in larger families following Dercon and Krishnan's (1998) methodology (see Appendix Table 13 ).

\subsubsection{A Multidimensional Analysis of Poverty}

\section{A. Description of Dimensions and Variables}

In literature on multidimensional poverty/well-being, selection of attributes and determination of their cut-off points are very important (Alkire 2007). There is no hard and fast rule for selecting attributes as these are constrained by the availability of reliable and comprehensive data which is a bottleneck in conducting multidimensional analyses in developing countries. However, the more the attributes, the better the indices will reflect the capabilities and functioning of individuals and the best measures of deprivation. Conventionally, these dimensions are related to the MDGs and their core functioning. The dimensions selected may represent both intrinsic and instrumental values. Besides this, weights attached to each attribute and their substitution degree matter for a comprehensive wellbeing analysis (Decancq and Lugo 2013; Maasoumi and Xu 2015). Yet there are common steps that one should follow in constructing a multidimensional index of poverty, wellbeing, or inequality. Alkire and Foster (2011) developed a dual cut-off approach for measuring multidimensional poverty which is an improvement over the union or intersection methods of determining deprivation for each attribute. They also developed the Adjusted Headcount Ratio $\left(\mathrm{M}_{0}\right)$ family of the multidimensional poverty measure. Alkire and Santos (2014) outlined the steps that one should follow in constructing a multidimensional index of poverty. The first step is defining a set of indicators which will be considered in the multidimensional measure. There is no rule for defining the set of attributes. However, one should use normative/value judgment in choosing the indicators which explain the 3 basic dimensions of the MPI measures (education, health, and living standards). Second is the setting of deprivation cut-offs for each indicator and applying the cut-offs to ascertain whether each person is deprived or not in each indicator. Then comes selecting the relative weights that each indicator has such that they add to one. This is followed by creating the weighted proportion of deprivations for each person, which can be called his/her deprivation score.

Determining the poverty cut-off, namely, the proportion of weighted deprivations that a person needs to experience to be considered multidimensionally poor and identifying each person as multidimensionally poor or not according to the selected poverty cut-off is the next step; this is followed by computing the proportion of people who have been identified as multidimensionally poor in the population. This gives the headcount ratio of multidimensional poverty, $\mathrm{H}$, also called the incidence of multidimensional poverty. Then comes computing the average share of weighted indicators in which the poor people are deprived. This entails adding up the deprivation scores of the poor and dividing them by the total 
number of poor people. This is the intensity of multidimensional poverty, A. Finally, the $\mathrm{M}_{0}$ measure has to be computed as the product of the 2 previous partial indices: $\mathrm{M}_{0}=\mathrm{H} \mathrm{x}$ A. MPI identifies people with joint disadvantages and as such contains more information than what the individual MDG indicators can offer (Alkire and Santos 2014). The latter is called the Dashboard approach and shows dimension-wise deprivation in the selected indicators (Ravallion 2011).

Following literature on the multidimensional poverty measure (Alkire and Foster 2007, 2011; Alkire and Santos 2014) we developed and measured poverty in a multidimensional index. As a first step, we selected attributes and their cut-off points (Table 2).

As explained in Table 2, our study used 6 dimensions with 14 variables to construct household deprivations. The first dimension measured conventional income or consumption expenditure poverty. Using the nationally defined poverty line, it defined the deprivation level as those households whose expenditure did not allow them to meet their basic calorie requirements; income/expenditure did not fully show the capabilities of the household. As a result, we included other measures of well-being such as education, health, housing, asset ownership, and energy use to capture a household's well-being from different perspectives. Three variables were used for constructing the index of health status of households-access to safe drinking water, type of kitchen used for cooking, and parental consultations-to measure potential health hazards and their immediate consequences on health. Rather than outcomes of diseases, derivers of health risks, levels of personal exposure, and the number of people exposed and disease rates can provide an idea of the overall global burden of diseases (GBD) due to indoor air pollution and unsafe drinking water (WHO 2002, 2007). Our study used education as the third dimension.

Two variables were used for constructing the education index: level of education of the household head and literacy rate of the household head. These 2 capture basic skills and educational attainments of household heads. Four variables were used for constructing the index of housing facilities: type of roof, occupancy status, toilet facility, and number of members per room (for measuring overcrowding of dwellings). Ownership of any of the 6 fixed household assets (refrigerator, radio, television, bicycle, motorcycle, and telephone) was used for measuring the asset deprivation of the households. Finally, energy use was used for capturing externalities that could result from energy use. It is claimed that reliance on traditional sources of energy reduces a household's well-being. Therefore, our study used three variables to construct the energy index and capture its effects on a household's well-being. Energy type for lighting, cooking, and type of stove used (mitad) were selected as indicators of energy deprivation. The cut-off at the individual attribute level (level of deprivation) was determined by looking at sample characteristics and realities in survey areas.

\section{B. Estimation of Relative Weights for Attributes of Multidimensional Poverty}

In a multidimensional analysis of poverty, besides identifying the attributes and determining their deprivation cut-off levels, analysts also worry about the choice of weights for each attribute/dimension in computing the aggregate index. The conventional approach of assigning equal weights has been criticized as people may not value the different indicators of well-being equally. As a result, several approaches to weighting have been developed for estimating weights used in aggregating the selected indicators in a composite index. Deutsch and Silber (2005) did a sytematic comparison of multidimensional poverty measurement using four approaches: theory of fuzzy set, information theory, efficiency 


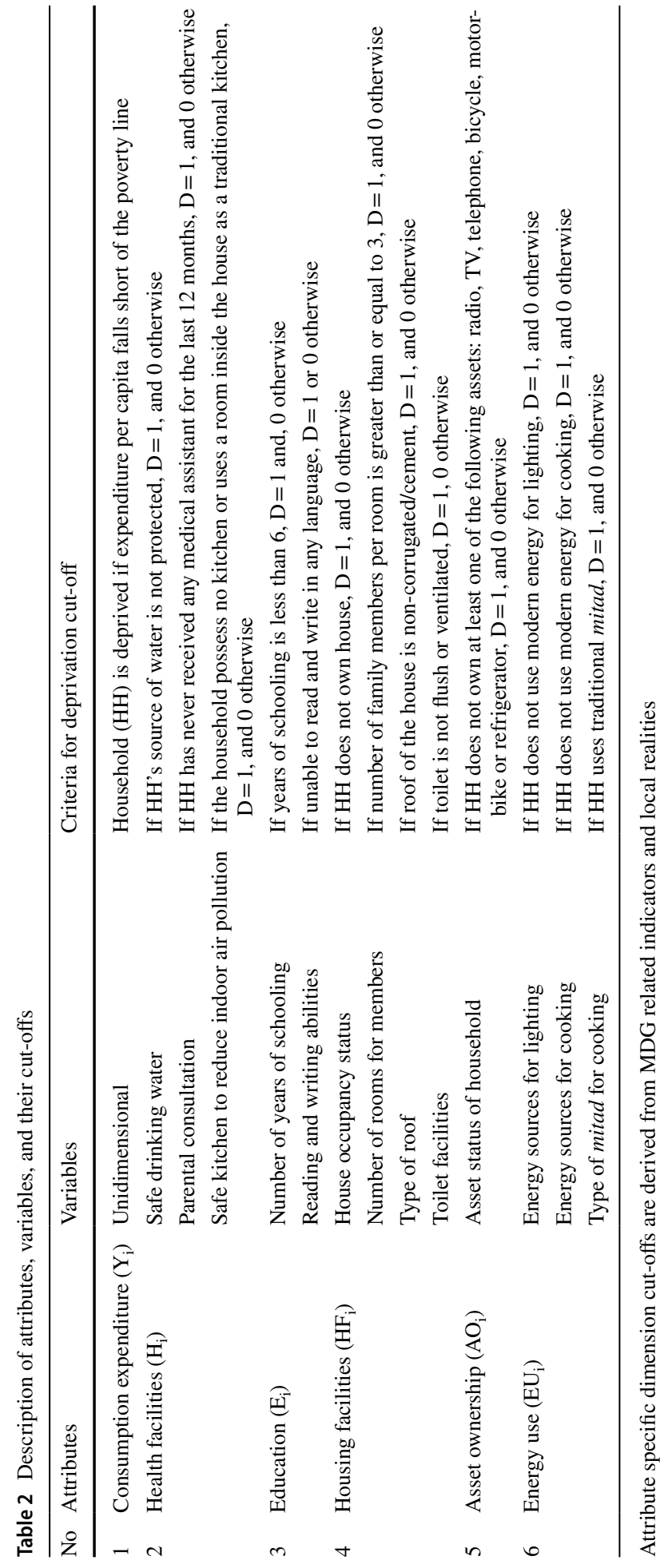


analysis, and axiomatic derivation of poverty indices. Housseima and Jaleleddine (2012) and Decancq and Lugo (2013) give comprehensive reviews of various approaches and their relative merits and demerits. In the non-axiomatic approach, multidimensional poverty or welfare is aggregated using the fuzzy set theory (Kim 2015; Zimmermann 2010), entropy approach (Maasoumi 1986; Maasoumi and Xu 2015), and the inertia approach which includes a principal component analysis, factor analysis, and a multi-correspondence analysis (Asselin 2002; Housseima and Jaleleddine 2012; Krzanowski 1987; Rao 1964).

Our study used the inertial approach for estimating weights in creating an aggregate index of multidimensional poverty from the selected attributes. In this approach, the data speaks for itself and the dimension to be used is determined within the analysis; it also helps in reducing dimensionality in creating the index. Since the variables used in the paper are discrete, we used a correspondence analysis (multiple correspondence analysis) for determining weights. The multiple correspondence analysis (MCA) helps examine patterns of relationships between various categorical variables as well as determining the weight of each indicator used in the construction of the multidimensional poverty index (Asselin 2002). It is a multivariate statistical tool used for reducing the number of dimensions. It reduces the initial $\mathrm{n}$ correlated dimensions to an uncorrelated index or components, where each component is a linear weighted combination of the initial variables that contain most of the information. MCA extracts the first factor which maintains the maximum information contained in the matrix. When all the variables used are transformed into a dichotomous form and coded as $0 / 1$ giving a total of $\mathrm{p}$ binary indicators, the MPI for each household $\mathrm{i}$ is computed as (Asselin 2002):

$$
\mathrm{MPI}_{i}=\frac{1}{K}\left(W_{1} I_{i 1}+W_{2} I_{i 2}+\ldots+W_{p} I_{i p}\right)
$$

where MPI stands for the vector of the weights, $I_{p}$ is a binary indicator of the status of the ith observation on the Pth indicator, and $\mathrm{Wp}$ is the weight (the score of the first standardized axis, score or $\sqrt{\lambda_{1}}$ of category $\mathrm{p}$ ). It may be the case that the estimated MPI using MCA develops a tendency of being negative in its lowest part. Due to difficulties in interpreting such results, this can be made positive by a translation using the absolute value of the average of the minimum categorical weights of each indicator (Cmin). Asselin (2002) presented this average minimum weight as:

$$
C_{\min }=\frac{\sum_{k=1}^{K} W_{\min }^{k}}{K}
$$

C. Theoretical Models for Analyzing Multidimensional Poverty and inequalities

For an analysis of poverty using a multidimensional index we followed Alkire and Foster $(2007,2011)$ given as:

$$
P(\alpha, X, Z)=\frac{1}{N} \sum_{i=1}^{N} \frac{1}{j} \sum_{j=1}^{J} W_{j}\left(\frac{Z_{j}-X_{i j}}{Z_{j}}\right)_{+}^{\alpha} I\left(d_{i} \geq d_{c}\right)
$$

where $\sum_{j=1}^{J} W_{j}=J, \mathrm{~d}_{\mathrm{i}}$ denotes the number of dimensions in which individual $i$ is deprived and $\mathrm{d}_{\mathrm{c}}$ denotes the normative dimensional cut-off. The Alkire and Foster method of computing multidimensional poverty has some limitations. Its second stage cut-off 
determination suffers from some arbitrariness. Further, it does not account for the degree of substitutability among the attributes used and also fails to exhibit the transfer principle (Deutsch and Silber 2005; Maasoumi and Xu 2015; Rippin 2010). However, this method has several advantages and some of its limitations are removed by using different techniques. In this regard, our study used estimated weights to reduce the limitations of this method.

We also analyzed the extent of multidimensional inequalities using the Araar (2009) index for $\mathrm{K}$ dimensions of poverty given by:

$$
I=\sum_{i=1}^{K} \varphi_{k}\left[\lambda_{k} I_{k}+\left(1-\lambda_{k}\right) C_{k}\right]
$$

where $\varphi_{k}$ is the weight attached to the dimension $k$ (the same weights estimated for multidimensional poverty using a factor analysis are used in our paper), $I_{k}$ and $C_{k}$ stand for the relative/absolute Gini and concentration indices of component $K$. The normative parameter $\lambda_{k}$ controls the sensitivity of the index to the inter-correlation between the dimensions.

\subsubsection{Theoretical Framework for Poverty Dominance}

This section presents models for decomposing poverty across different groups (gender, age, education, and rural-small town). A test of stochastic dominance of various degrees for distribution of poverty and inequalities is well-documented in literature on poverty and in inequality analyses (Anderson 1996; Atkinson 1987; Barrett and Donald 2003; Davidson and Duclos 2000; Maasoumi and Heshmati 2000, 2008). In line with the theoretical foundation outlined in Davidson and Duclos (2000) we assumed that there were 6 distributions ( $\mathrm{A}$ and $\mathrm{B}$ ) of welfare measures (say consumption expenditure or MPI), characterized by cumulative distribution functions (CDFs) of $\mathrm{F}_{\mathrm{A}}$ and $\mathrm{F}_{\mathrm{B}}$, with support contained in the nonnegative real line. Let $\mathrm{D}^{1} \mathrm{~A}(\mathrm{x})=\mathrm{F}_{\mathrm{A}}(\mathrm{x})$ and:

$$
D_{A}^{s}(x)=\int_{0}^{x} D_{A}^{(s-1)}(y) d y
$$

For any integer $s \geq 2$, and let $D_{s} B(x)$ be defined analogously, then we can express $D_{s}(x)$ for any order s as:

$$
D^{s}(X)=\frac{1}{(s-1) !} \int_{0}^{x}(x-y)^{s-1}(y) d F(y)
$$

Distribution $\mathrm{B}$ is said to dominate distribution A stochastically at order $\mathrm{s}$ if $D_{A}^{s}(x) \geq D_{B}^{s}(x)$ for all $\mathrm{x} \in \Re$. For strict dominance, the inequality must hold strictly over some interval of the positive measure. The important orders in the stochastic dominance test are the first and second orders. First order stochastic dominance (FSD) of A by B up to a poverty line $\mathrm{z}$ implies that $\mathrm{F}_{\mathrm{A}}(\mathrm{x}) \geq \mathrm{F}_{\mathrm{B}}(\mathrm{x})$ for all income levels less than the poverty line. It is tantamount to saying that the proportion of individuals below the poverty line is always greater in A than in B for any poverty line not exceeding z. Similarly, second order stochastic dominance (SSD) of $\mathrm{A}$ by $\mathrm{B}$ up to a poverty line $\mathrm{z}$ implies that $\mathrm{D}_{\mathrm{A}}{ }(\mathrm{x}) \geq \mathrm{D}^{2}{ }_{\mathrm{B}}(\mathrm{x})$, that is: 


$$
\int_{0}^{x}(x-y) d F_{A}(y) \geq \int_{0}^{x}(x-y) d F_{B}(y)
$$

In line with this theoretical foundation, we conducted a dominance analysis of both unidimensional and multidimensional indices of poverty for different social groups.

\subsubsection{Econometric Models for Determinants of Poverty}

There are various techniques for identifying the determinants of poverty. The most widely used method is a regression analysis. Two techniques are most frequently used in a regression analysis. The first one explains the level of consumption expenditure per capita as a function of covariates and the second technique explains the probability of households falling into poverty and its determinants using probit or logit regressions. In this case, the dependent variable is binary, taking the value of 1 if the household or individual is poor and zero otherwise. We used the second method for examining the determinants of poverty in rural and small urban areas in Ethiopia. The probability of households falling into poverty is modeled as a function of the household head's characteristics: age, gender, marital status, education, household's characteristics like size, and regional level characteristics such as regional dummies and access to credit.

First, we determined a household's status using consumption expenditure as being poor or not:

$$
\mathrm{SES}_{i}= \begin{cases}1, & \text { if household is poor } \\ 0, & \text { otherwise }\end{cases}
$$

where $\mathrm{SES}_{\mathrm{i}}$ stands for social-economic status and it shows the status of households using either consumption expenditure or the multidimensional index. The probability that a household is poor given the covariates can be represented by a cumulative distribution function given as:

$$
\operatorname{Pr}\left(S E S_{i}=1 \mid X\right)=F\left(X_{1}^{\prime} \beta\right)
$$

This cumulative distribution function gives a logit or probit model on the distributional assumption for the dataset (Achia et al. 2010; Cameron and Trivedi 2005; Green 2003). Assuming logistic distribution, we specify the logit model as:

$$
\operatorname{Pr}\left(\operatorname{SES}_{i}=1 / X\right)=\frac{\exp \left(X_{i}^{\prime} \beta\right)}{1+\exp \left(X_{i}^{\prime} \beta\right)}
$$

where $X_{i}$ stands for predictors such as age, gender, marital status, and educational level of the household head, household size, type of residence (rural or small town), regional dummies, and access to credit. Equation 11 has no sound economic interpretation and hence we estimated the log odds ratio (logistic regression) model as:

$$
\ln \left(\frac{p}{1-p}\right)=\beta_{0}+\beta_{1} X_{1}+\beta_{2} X_{2}+\ldots . .+\beta_{n} X_{n}
$$

where $X_{1}$ to $X_{n}$ stand for the covariates used as the determinants of poverty and $p$ denotes the probability that a household is poor. Besides, the marginal effect is estimated after the logit model and we have interpreted the coefficients from this part. 
Table 3 Descriptive statistics of the major variables

\begin{tabular}{|c|c|c|c|c|}
\hline \multirow[t]{2}{*}{ Variables } & \multicolumn{2}{|l|}{2011} & \multicolumn{2}{|l|}{2014} \\
\hline & Mean & Std. Dev & Mean & Std. Dev \\
\hline Household size & 4.86 & 2.38 & 4.91 & 2.36 \\
\hline Household size in adult equivalence (AE) & 3.93 & 1.95 & 3.96 & 1.93 \\
\hline Age of household head & 44.23 & 15.63 & 45.84 & 15.32 \\
\hline Annual food consumption expenditure & $26,553.64$ & $82,034.7$ & $19,573.04$ & $45,911.00$ \\
\hline Annual non-food consumption expenditure & 3280.57 & 9319.89 & 4311.92 & 5064.84 \\
\hline Annual education expenditure & 202.43 & 735.80 & 219.00 & 551.75 \\
\hline Annual total expenditure & $30,036.64$ & $82,855.5$ & $24,103.97$ & $46,943.89$ \\
\hline Nominal per capita expenditure per AE & 8350.83 & $25,197.01$ & 6772.09 & $12,548.99$ \\
\hline Real per capita expenditure per $\mathrm{AE}$ & 8097.76 & $24,617.85$ & 6703.72 & $11,903.92$ \\
\hline
\end{tabular}

\section{Results and Discussion}

This section presents detailed results and their discussion. Table 3 gives the results of a descriptive statistical analysis of the major variables. This is followed by a poverty analysis using the Foster, Greer, and Thorbecke (FGT) family for the unidimensional measure. It also analyzes tests for different orders of stochastic dominance and sub-group decomposition of poverty. It also presents and discusses concise results of inequalities for both unidimensional and multidimensional indicators. Finally, it presents the results of the multidimensional poverty measure using the Alkire-Foster methodology and econometric results for identifying the determinants of poverty.

\subsection{Descriptive Statistics' Results of Major Variables}

Adjusting income or expenditure for family composition is a pertinent factor in any poverty analysis. Income per capita's computation, as well as the economies of scale's argument for bulk purchases, is the reason for an explicit consideration of family size for a poverty analysis. Thus, this study used the adult equivalence (AE) family size to consider this. It converted household size to adult male equivalence accounting for age and gender compositions. As given in Table 3, average household size was higher than the adult equivalence family size. In the 2014 survey, there was a slight increase in family size as well as its adult equivalence yet it showed a similar degree of dispersion. Besides, the age of the household head was on average about 44 years in 2011 and 46 years in 2014. Table 3 also gives different components of a household's consumption expenditure. On average, a household spent about 26,553 Birr, 3280 Birr, and 202 Birr per year in 2011 and 19,573 Birr, 4311 Birr, and 219 Birr per year in 2014 on food consumption, non-food consumption, and education respectively. Average annual total expenditure decreased from 30,036 Birr per year in 2011 to 24,103 Birr per year in 2014.

Both nominal and real per capita adult equivalence expenditure showed a decreasing trend in 2014. The figures for the standard deviation clearly show that there were observable variations among households regarding various components of consumption 
Table 4 Frequency distribution of categorical variables

\begin{tabular}{llll}
\hline Variables & & 2011 & 2014 \\
\hline Sex of household head & Male (\%) & 75.48 & 74.12 \\
Marital status of household head & Married (\%) & 76.28 & 74.49 \\
Literacy status of household head & Read and write (\%) & 40.61 & 41.05 \\
Household members' use of credit & Yes (\%) & 23.88 & 26.75 \\
\hline
\end{tabular}

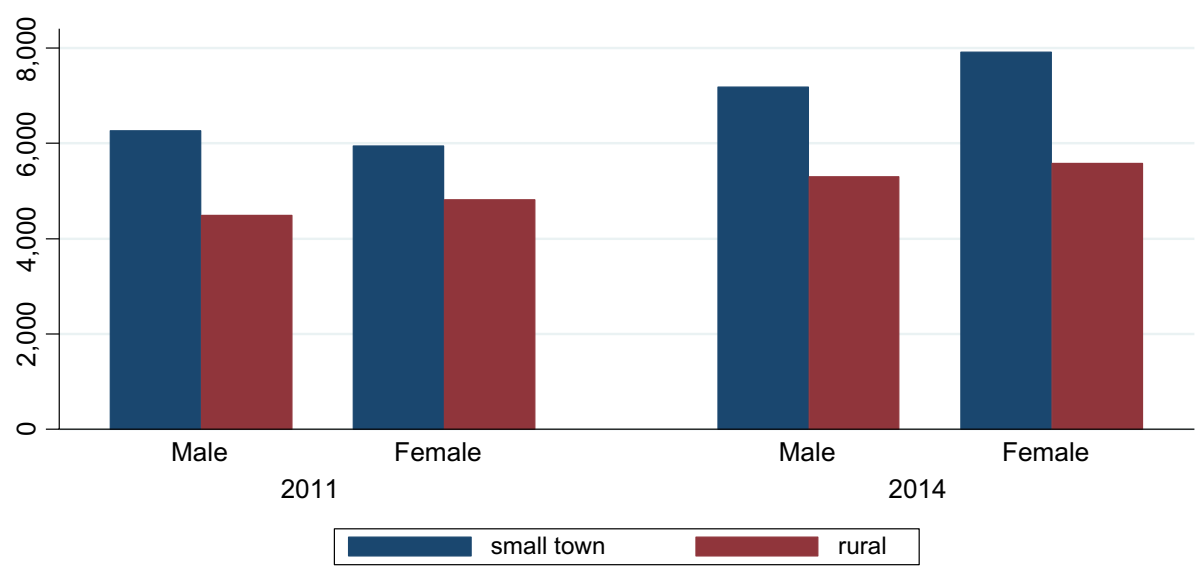

Fig. 1 Bar chart of consumption expenditure by year, area, and gender

expenditure. This could signal persistence of significant inequalities as explained later using the inequality measures.

There was a strong relationship between gender and headship of the household. In 2011, about 76 percent of the households were male-headed while only 24 percent were headed by females. In 2014 there was a slight change in these figures as 74 percent households had male heads and 26 percent had female heads. An orthodox practice of assigning a male as the head of a household in a developing country still exists. Headship and gender differences have considerable implications for resource allocations and poverty severity in the gender dimension. Similarly, as we can see in Table 4, the marital status of the household head, literacy level, and beneficiaries of credit from different sources did not show considerable variations between the 2 survey years. Credit use does not seem to be a common practice in rural and small towns in Ethiopia. Only about 24 percent and 27 percent of the respondents were credit users in 2011 and 2014 respectively. Perhaps rural households are credit constrained with limited access to credit which constrains their productivity and worsens their poverty situation.

Distribution of consumption expenditure significantly varied over time, across regions, and gender wise. As we can see in Fig. 1, poverty is clearly shows a rural dimension. Mean per capita consumption expenditure was higher for both genders in small towns as compared to those in rural areas. The gap between rural-small towns tended to be wider in the 2014 survey. Further a disaggregate analysis of the data across regional states of the country indicates observable variations in consumption expenditure. 
Table 5 FGT poverty indices by year, area, and sex of household head

\begin{tabular}{|c|c|c|c|c|c|c|c|c|c|}
\hline \multirow{2}{*}{$\begin{array}{l}\text { Poverty Measured over * } \\
\text { Poverty index }\end{array}$} & \multicolumn{3}{|l|}{ Year } & \multicolumn{3}{|l|}{ Area } & \multicolumn{3}{|c|}{ Sex of HH head } \\
\hline & 2011 & 2014 & Pop \# & Rural & Small town & Pop & Male & Female & Pop \\
\hline Headcount $\left(\mathrm{P}_{0}\right)$ & 41.0 & 32.0 & 36.0 & 36.0 & 20.0 & 36.0 & 37.0 & 30.0 & 36.0 \\
\hline Poverty gap $\left(\mathrm{p}_{1}\right)$ & 14.0 & 9.0 & 11.0 & 11.0 & 6.0 & 11.0 & 11.0 & 9.0 & 11.0 \\
\hline Squared poverty gap $\left(\mathrm{P}_{2}\right)$ & 6.0 & 4.0 & 5.0 & 5.0 & 3.0 & 5.0 & 5.0 & 4.0 & 5.0 \\
\hline
\end{tabular}

*Relative poverty line (50\% of the mean income of the sample household) is used for the Foster, Greer, and Thorbecke (FGT) computation; \#Pop stands for population

As we can see in Fig. 1, the rural-urban, gender, and time dimensions of the poverty analysis need serious attention. We can, therefore, draw an inference for suitable policy interventions: one-size-fits-all poverty reduction policies may not lead to impressive results. Prudent policies targeted at reducing poverty, if not eradicating it, should take into account the realities of households and regional disparities.

\subsection{Extent of Poverty Using FGT and Multidimensional Poverty Indices}

The results presented in the descriptive statistics can be further strengthened by empirical results of a poverty analysis using the FGT family reported in Table 5. A relative poverty line was used for computing FGT poverty indices unlike the conversant one-dollar a day absolute poverty line. A 50 percent mean consumption expenditure of households was used as a relative poverty line which also accounted for the extent of inequalities in incomes.

Table 5 shows intensity, severity, and depth of poverty using consumption expenditure per adult equivalence by year, the area of residence, and the gender of the household head. There was a substantial decline in relative poverty levels between the 2 survey years. In 2011, 41 percent of the population was poor while this declined to 32 percent in 2014. The rural dimension of poverty is further confirmed from the results in Table 5-36 percent of rural dwellers were poor while only 20 percent of the urban dwellers were poor. Table 5 also shows that relative poverty was more severe for male-headed households. The results also indicate that 37 percent of the male-headed households were poor as compared to 30 percent headcount poverty for female-headed households. The overall poverty headcount was 36 percent for the sample respondents, which is quite a significant number. The results further show that the severity and depth of poverty had observable variations over time with the area of residence and the sex of the household head. The regional profile of poverty measured by the FGT index is presented in Table 6 . The extent of poverty varied considerable across regions.

The poverty headcount, gap, and severity indices in Table 6 can be complemented by cumulative poverty gap curves by gender and their differences (see Figs. 2 and 3).

As we can see in Figs. 2 and 3 there was an observable gender-wise poverty gap for the different percentiles. At the lower percentiles, the difference was insignificant but as the percentile increased, the gap became wider and in the later percentile the difference became constant. Besides, the FGT poverty curves also show the sensitivity of poverty measures to the poverty line. For $\alpha=0,1$, and 2, the respective curves disaggregated by sex of household head are given in Figs. 4, 5, and 6. 
Table 6 The Foster, Greer, and Thorbecke (FGT) poverty indices for different regions

\begin{tabular}{llll}
\hline FGT poverty Indices using the relative poverty measure & & \\
\hline Region & Head count (P0) & Poverty gap (P1) & $\begin{array}{l}\text { Squared } \\
\text { poverty gap } \\
\text { (P2) }\end{array}$ \\
\hline Tigray & & 0.04 \\
Afar & 0.36 & 0.10 & 0.02 \\
Amhara & 0.30 & 0.07 & 0.05 \\
Oromia & 0.47 & 0.13 & 0.03 \\
Somalie & 0.25 & 0.07 & 0.04 \\
Benshagul Gumuz & 0.35 & 0.10 & 0.08 \\
SNNP & 0.45 & 0.17 & 0.08 \\
Gambelia & 0.41 & 0.16 & 0.07 \\
Harari & 0.43 & 0.15 & 0.01 \\
Diredwa & 0.11 & 0.02 & 0.02 \\
Aggregate & 0.24 & 0.06 & 0.05 \\
\hline
\end{tabular}

\section{Cumulative poverty gap Curves}

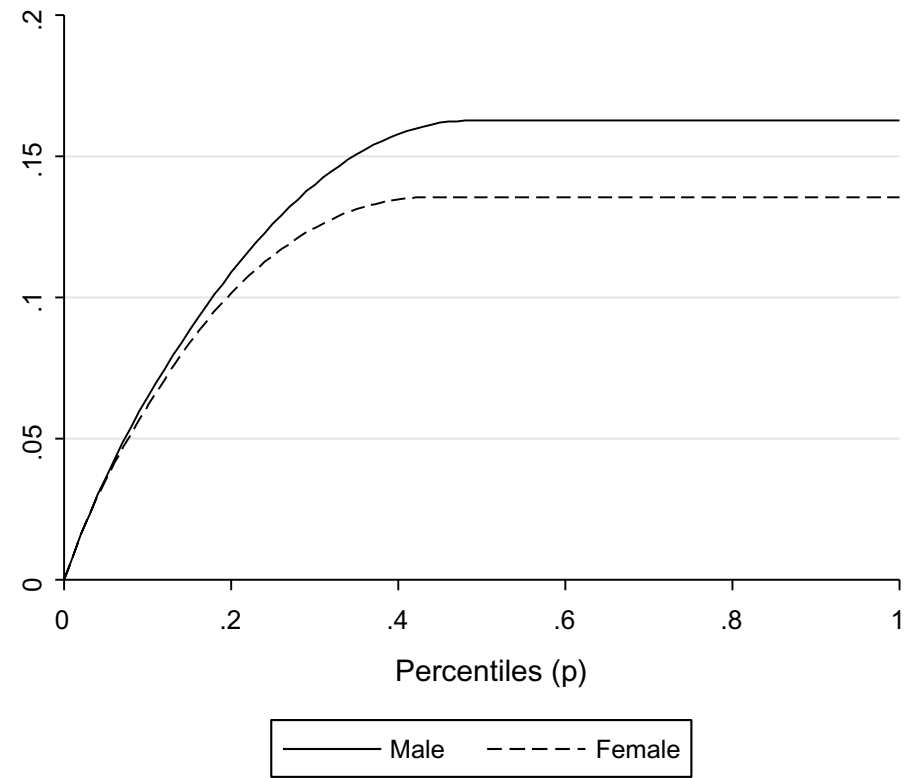

Fig. 2 Gender-wise cumulative poverty gap

The FGT curves presented in Figs. 4, 5, and 6 carry significant policy implications for examining how the level of poverty varies as the poverty line changes. It also helps test poverty dominance between 2 distributions and testing for pro-poor growth conditions. As we can see in these figures, headcount, poverty gap, and poverty severity show consistent dominance of poverty for male-headed households as compared to female-headed ones. 


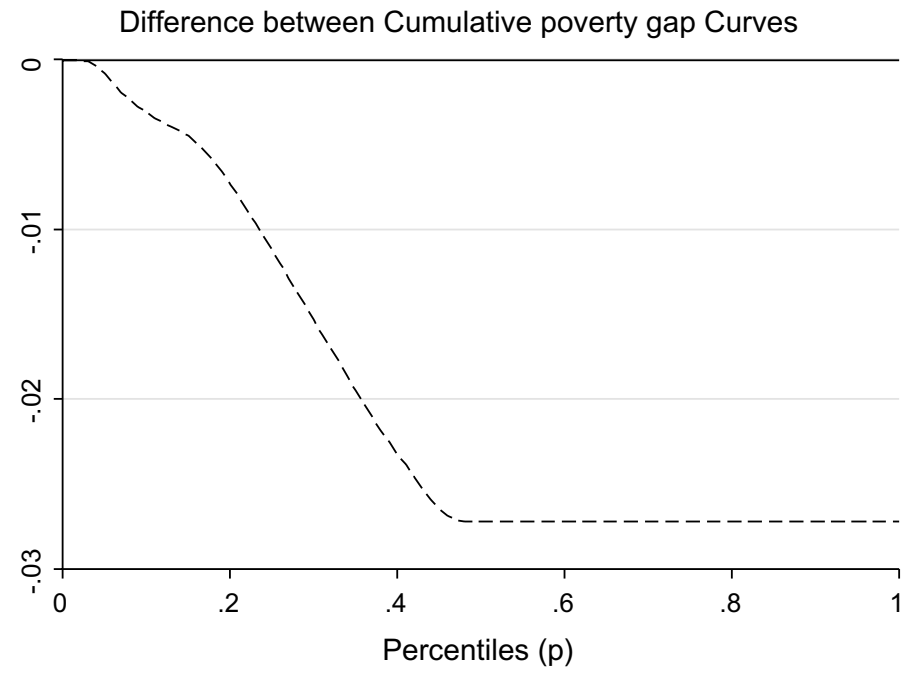

Null Horizontal Line $\quad-----$ CPG_Female - CPG_Male

Fig. 3 Difference between CPG

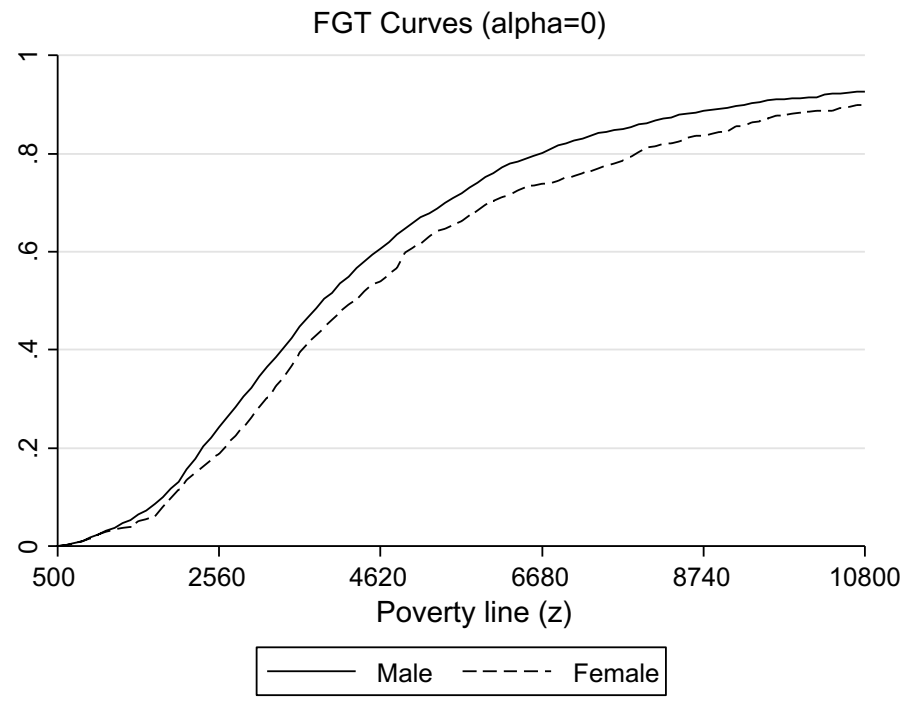

Fig. 4 FGT curve for $\alpha=0$

Decomposing poverty into different groups and an analysis of their contribution to poverty levels is pertinent for targeting policies at reducing poverty. The most frequently used decomposition of poverty is on variables such as sources of income, occupation, gender, and area of residence. A decomposition of gender-wise poverty is given in Table7.

As we can see in Table 7, absolute contribution to poverty indices depends on the underlying economic status of the sub-group while the relative contribution must do 


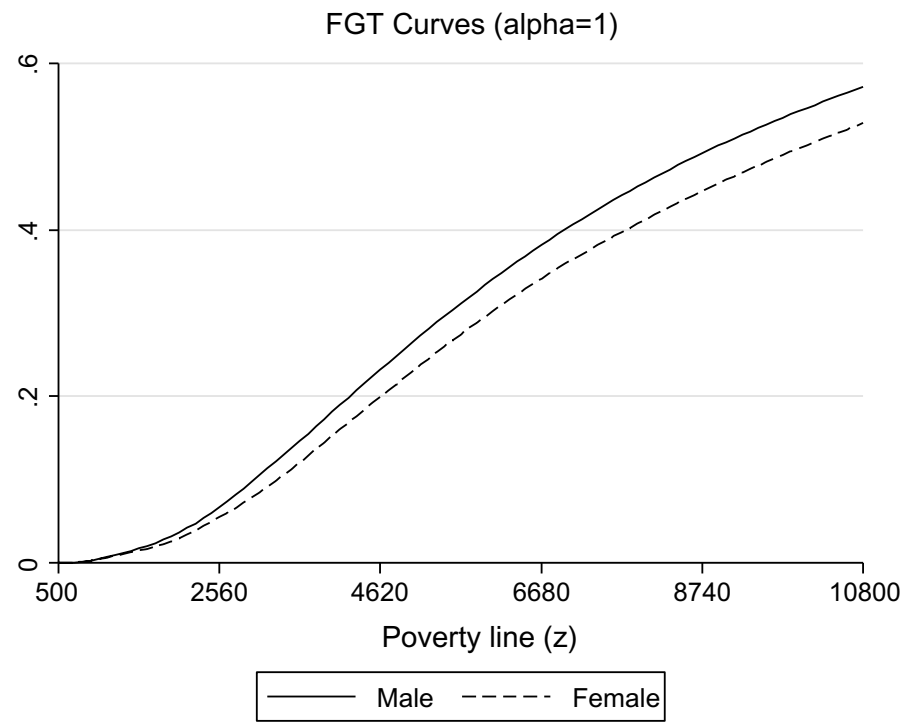

Fig. 5 FGT curve for $\alpha=1$

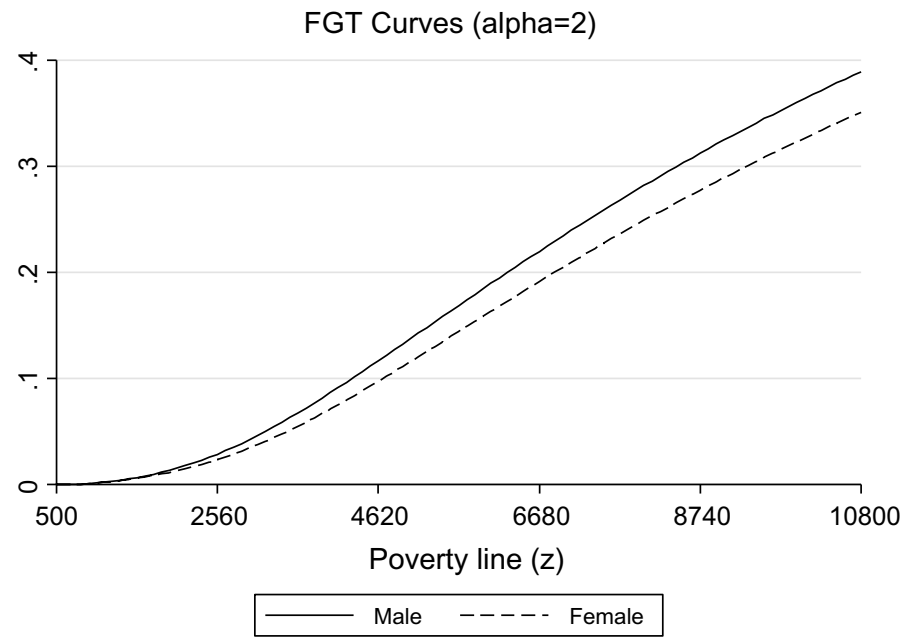

Fig. 6 FGT curve for $\alpha=2$

with the relative proportion of each sub-group in the concerned population. Thus, the contribution of female-headed households to the overall poverty status was lower due to a lower number of female-headed households in the study area.

Similarly, an analysis of stochastic dominance of consumption by sub-groups helps us see the nature of poverty in our analysis. Stochastic dominance conditions provide a robust ordinal comparison of distribution of poverty among different groups. Figures 7 and 8 show that male-headed households' consumption expenditure first order (FSD) 
Table 7 Decomposition of the FGT index by gender of the household head

\begin{tabular}{|c|c|c|c|c|c|c|c|c|c|}
\hline \multirow[t]{2}{*}{ Index/groups } & \multicolumn{3}{|c|}{ Headcount } & \multicolumn{3}{|c|}{ Poverty gap } & \multicolumn{3}{|c|}{ Poverty severity } \\
\hline & Male & Female & Pop & Male & Female & Pop & Male & Female & Pop \\
\hline FGT index & $\begin{array}{c}0.37 \\
(0.02)\end{array}$ & $\begin{array}{c}0.30 \\
(0.03)\end{array}$ & $\begin{array}{c}0.36 \\
(0.02)\end{array}$ & $\begin{array}{c}0.11 \\
(0.01)\end{array}$ & $\begin{array}{c}0.09 \\
(0.01)\end{array}$ & $\begin{array}{c}0.11 \\
(0.01)\end{array}$ & $\begin{array}{c}0.05 \\
(0.00)\end{array}$ & $\begin{array}{c}0.04 \\
(0.01)\end{array}$ & $\begin{array}{c}0.05 \\
(0.00)\end{array}$ \\
\hline Share of all & $\begin{array}{c}0.86 \\
(0.01)\end{array}$ & $\begin{array}{c}0.14 \\
(0.01)\end{array}$ & $\begin{array}{c}1.00 \\
(0.00)\end{array}$ & $\begin{array}{c}0.86 \\
(0.01)\end{array}$ & $\begin{array}{c}0.14 \\
(0.01)\end{array}$ & $\begin{array}{c}1.00 \\
(0.00)\end{array}$ & $\begin{array}{c}0.86 \\
(0.01)\end{array}$ & $\begin{array}{c}0.14 \\
(0.01)\end{array}$ & $\begin{array}{c}1.00 \\
(0.00)\end{array}$ \\
\hline Abs. contr & $\begin{array}{c}0.32 \\
(0.02)\end{array}$ & $\begin{array}{c}0.04 \\
(0.00)\end{array}$ & $\begin{array}{c}0.37 \\
(0.02)\end{array}$ & $\begin{array}{c}0.10 \\
(0.01)\end{array}$ & $\begin{array}{c}0.01 \\
(0.00)\end{array}$ & $\begin{array}{c}0.11 \\
(0.01)\end{array}$ & $\begin{array}{c}0.04 \\
(0.00)\end{array}$ & $\begin{array}{c}0.01 \\
(0.00)\end{array}$ & $\begin{array}{c}0.05 \\
(0.00)\end{array}$ \\
\hline Relative contr & $\begin{array}{c}0.88 \\
(0.01)\end{array}$ & $\begin{array}{c}0.12 \\
(0.01)\end{array}$ & $\begin{array}{c}1.00 \\
(0.00)\end{array}$ & $\begin{array}{c}0.88 \\
(0.01)\end{array}$ & $\begin{array}{c}0.12 \\
(0.01)\end{array}$ & $\begin{array}{c}1.00 \\
(0.00)\end{array}$ & $\begin{array}{c}0.88 \\
(0.02)\end{array}$ & $\begin{array}{c}0.12 \\
(0.02)\end{array}$ & $\begin{array}{c}1.00 \\
(0.00)\end{array}$ \\
\hline
\end{tabular}

Standard errors are in parenthesis

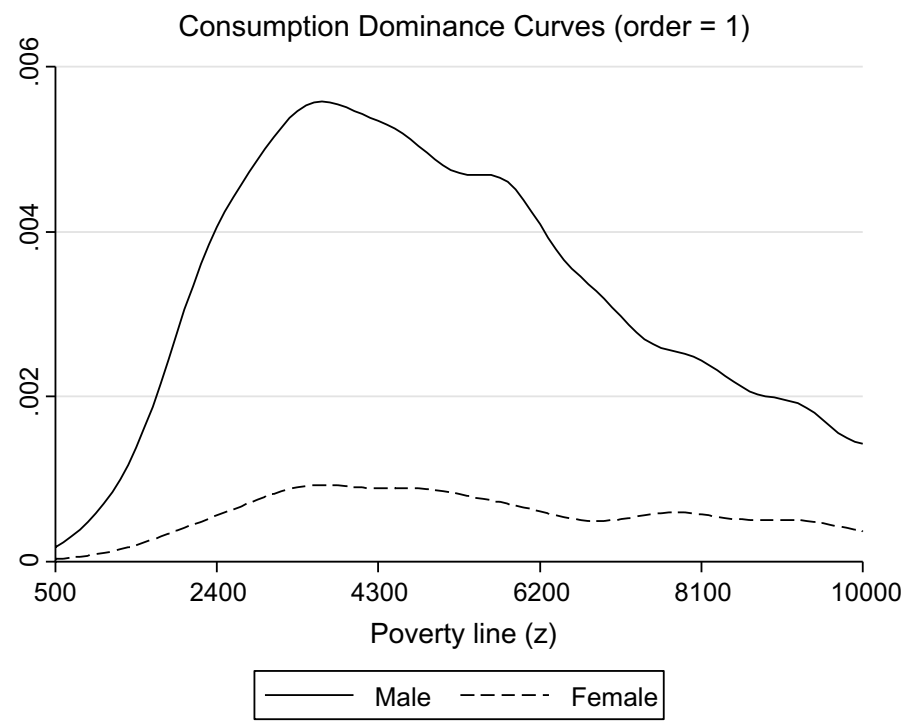

Fig. 7 FSD of consumption by gender

and second order (SSD) stochastic dominated female-headed households' consumption expenditure.

However, a regional consumption dominance condition is not observed in the results. For each region both first order stochastic dominance and second order stochastic dominance showed no unique dominance relationship (Figs. 9 and 10).

An analysis of the distributional patterns of consumption expenditure sheds light on the degree of inequalities for different groups. The degree of income inequality as presented by the Lorenz curve (Figs. 11 and 12), shows observable inequalities of income over time and by the area of residence. 


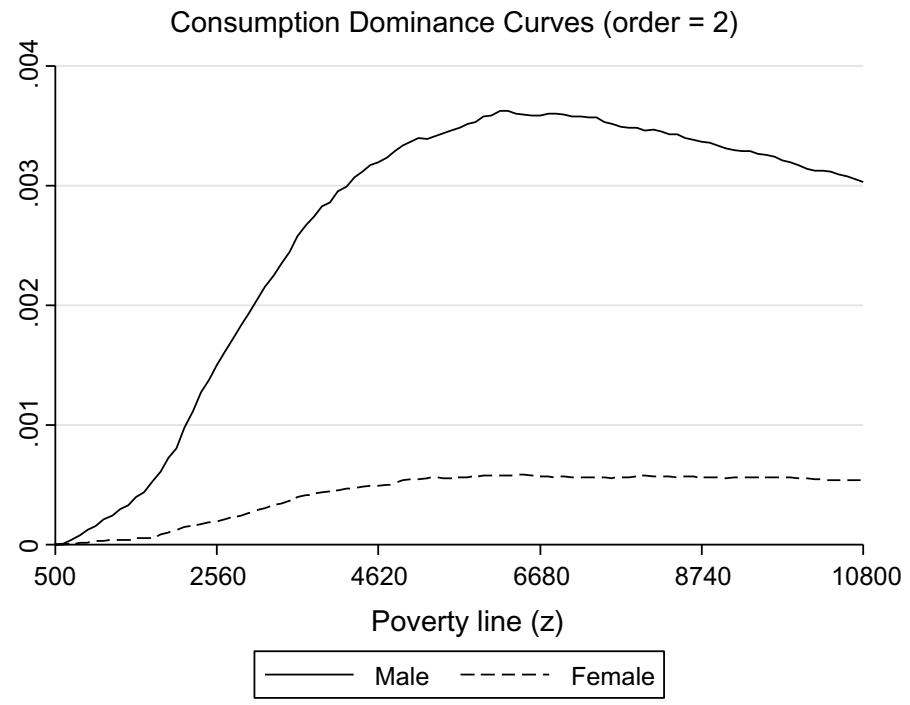

Fig. 8 SSD of consumption by gender

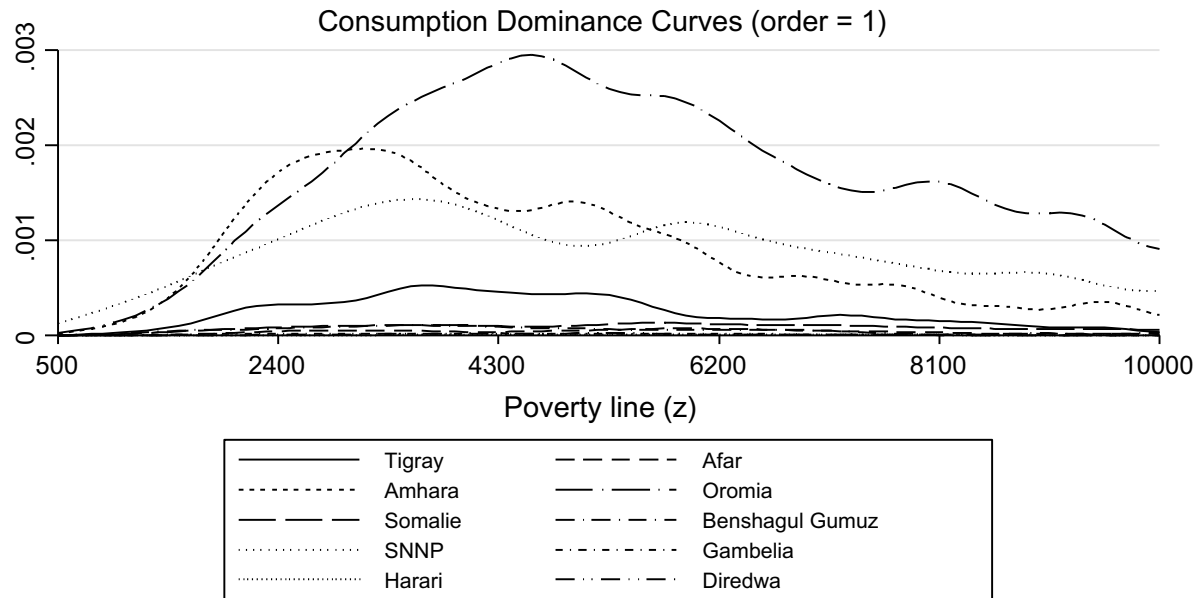

Fig. 9 FSD of consumption expenditure by region

In addition to a unidimensional analysis of poverty, we also conducted its multidimensional analysis. Since poverty is a multidimensional phenomenon, the unidimensional measures presented earlier partially show the well-being status of households. Thus, using 6 dimensions with 14 variables we computed a multidimensional index of poverty. This index shows that the extent of poverty was quite high in Ethiopia if one considers the nonincome dimensions of households' well-being (Table 8).

As we can see in Table 8, there was an observable improvement in the income deprivation index between the 2 survey years. In 2011 about 41 percent of the respondents were poor by the consumption expenditure indicator but this figure decreased to 32 


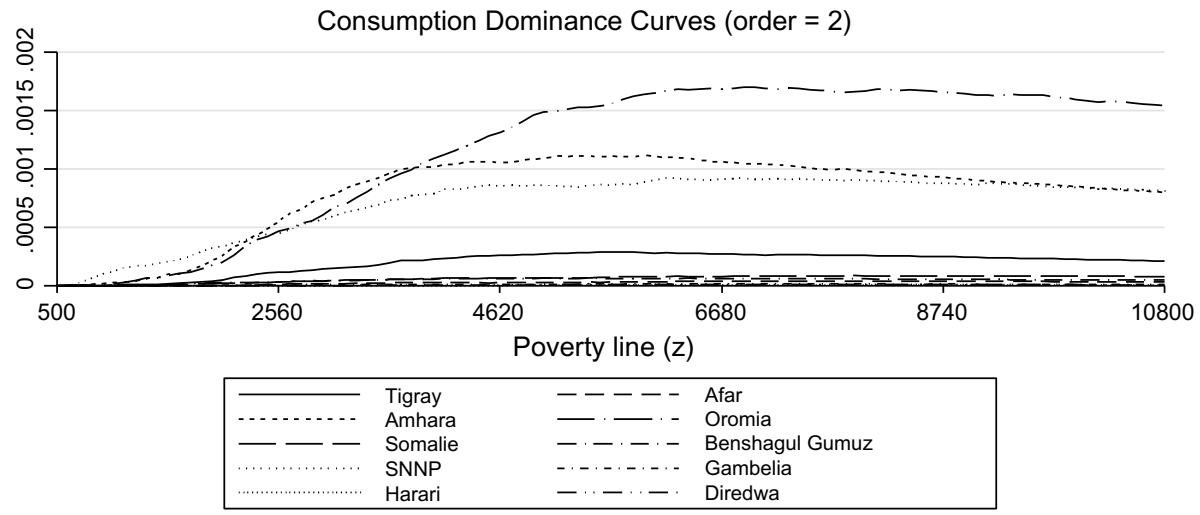

Fig. $10 \mathrm{SSD}$ of consumption expenditure by region

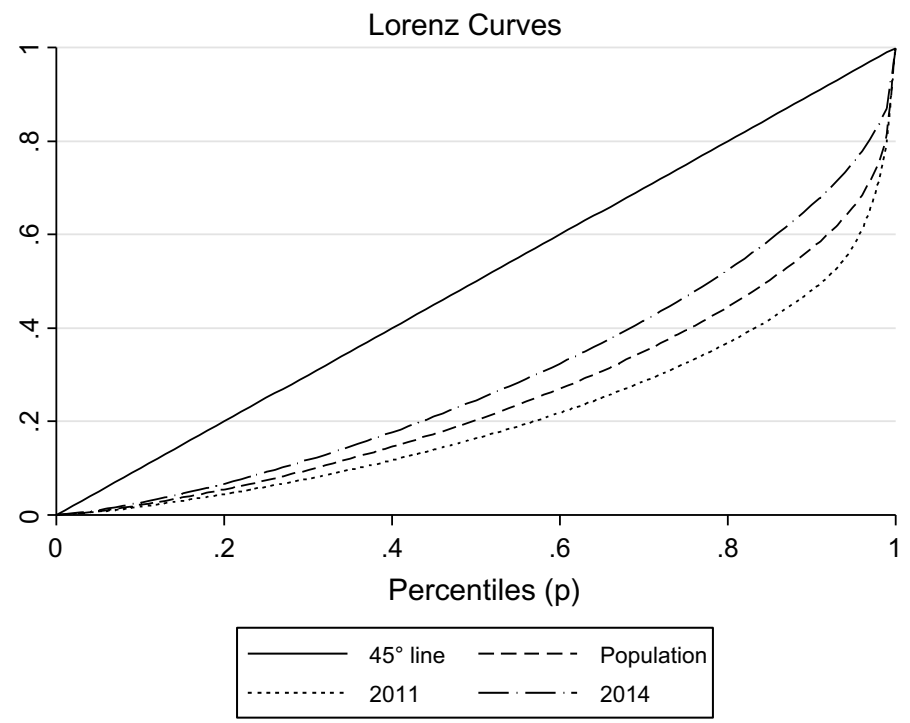

Fig. 11 Lorenz curves by year

percent in 2014. However, the non-income indicators of well-being selected show that there were high levels of deprivation in health, education, housing, asset ownership, and energy use indicators.

The extent of multidimensional poverty depends on the weights used for each indicator while constructing the index. The results of 2 methods are presented in Table 9.

As can be seen in Table 9 the extent of multidimensional poverty is lower with weights derived from data using multiple correspondence analyses. As a result, we present the poverty status of households in different groups using weights generated from the data applying MCA (Table 10). 


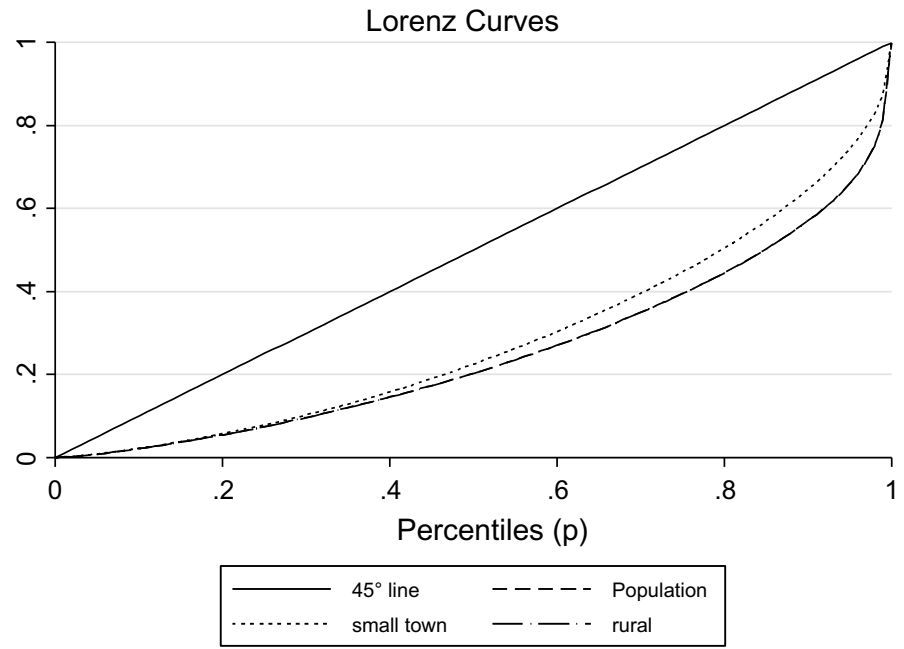

Fig. 12 Lorenz curves by area

Table 8 Deprivation levels of each indicator by year

\begin{tabular}{|c|c|c|c|c|c|c|c|c|c|c|c|c|c|c|}
\hline \multirow[t]{2}{*}{ Year } & \multirow{2}{*}{$\begin{array}{l}\text { Cons Exp } \\
\mathrm{Ci}\end{array}$} & \multicolumn{3}{|c|}{ Health } & \multicolumn{2}{|c|}{ Education } & \multicolumn{4}{|c|}{ Housing } & \multirow{2}{*}{$\begin{array}{l}\text { Asset } \\
\text { AOi }\end{array}$} & \multicolumn{3}{|c|}{ Energy use } \\
\hline & & $\mathrm{H}_{1}$ & $\mathrm{H}_{2}$ & $\mathrm{H}_{3}$ & $\mathrm{Ed}_{1}$ & $\mathrm{Ed}_{2}$ & $\mathrm{HS}_{1}$ & $\mathrm{HS}_{2}$ & $\mathrm{HS}_{3}$ & HS4 & & Eng1 & Eng2 & Eng3 \\
\hline 2011 & 41.0 & 74.0 & 67.0 & 66.6 & 63.5 & 59.4 & 13.2 & 56.6 & 57.0 & 95.8 & 53.1 & 64.0 & 98.3 & 97.0 \\
\hline 2014 & 32.0 & 70.8 & 55.3 & 62.4 & 61.4 & 58.9 & 13.4 & 52.2 & 50.8 & 94.5 & 68.6 & 49.1 & 98.1 & 97.1 \\
\hline
\end{tabular}

The variables used for each indicator are the same as those defined in Table 2

Table 9 Multidimensional poverty index using different weights

\begin{tabular}{llllll}
\hline Groups & \multicolumn{2}{l}{ Using equal weights } & & \multicolumn{2}{l}{$\begin{array}{l}\text { Using weights } \\
\text { from MCA }\end{array}$} \\
\cline { 2 - 3 } \cline { 5 - 6 } & 2011 & 2014 & & 2011 & 2014 \\
\hline Head count (H) & 0.80 & 0.77 & & 0.83 & 0.77 \\
Intensity (A) & 0.58 & 0.58 & & 0.58 & 0.56 \\
MPI & 0.46 & 0.45 & & 0.48 & 0.43 \\
\hline
\end{tabular}

Table 10 Multidimensional poverty index by year, sex of household head, and area

\begin{tabular}{|c|c|c|c|c|c|c|c|c|c|}
\hline \multirow[t]{2}{*}{ Groups } & \multicolumn{3}{|l|}{ Year } & \multicolumn{3}{|c|}{ Sex of $\mathrm{HH}$ head } & \multicolumn{3}{|c|}{ Area of residence } \\
\hline & 2011 & 2014 & Pop & Male & Female & Pop & Rural & Urban & Pop \\
\hline Head count $(\mathrm{H})$ & 0.83 & 0.77 & 0.80 & 0.81 & 0.70 & 0.80 & 0.89 & 0.43 & 0.80 \\
\hline Intensity (A) & 0.58 & 0.56 & 0.58 & 0.58 & 0.56 & 0.58 & 0.67 & 0.61 & 0.58 \\
\hline MPI & 0.48 & 0.43 & 0.46 & 0.47 & 0.39 & 0.46 & 0.52 & 0.21 & 0.46 \\
\hline $\begin{array}{l}\text { Inequality among } \\
\text { the MPI poor }\end{array}$ & 0.32 & 0.34 & 0.33 & 0.34 & 0.25 & 0.33 & 0.32 & 0.65 & 0.33 \\
\hline
\end{tabular}


Table 11 Relative contribution of dimensions to MPI estimated each year $(\%)$

\begin{tabular}{lrr}
\hline Dimensions & \multicolumn{2}{c}{$\begin{array}{l}\text { Contribution of each } \\
\text { dimension to MPI in }\end{array}$} \\
\cline { 2 - 3 } & 2011 & 2014 \\
\hline Consumption expenditure index & 15.60 & 13.70 \\
Health index & 29.40 & 27.80 \\
Education index & 9.80 & 10.20 \\
Housing facility Index & 21.20 & 21.40 \\
Asset ownership index & 3.20 & 5.60 \\
Energy use index & 20.90 & 20.60 \\
\hline
\end{tabular}

Following the Alkire and Foster $(2007,2011)$ methodology a person is said to be multidimensionally poor if he or she is deprived in at least one-third of the weighted indicators used in an analysis. In other words, the cut-off point used for identifying an individual as multidimensionally poor is 33.3 percent. As presented in Table 10, the proportion of the population that was multidimensionally poor $(\mathrm{H})$ was about 80 percent. The intensity of multidimensional poverty (A) shows the average proportion of indicators in which the poor people were deprived. The poor were deprived in about 58 percent of the indicators. A detailed analysis of multidimensional poverty for different groups shows that poverty incidence was 83 percent and 77 percent in 2011 and 2014 respectively. There was about a 7 percent decline in the incidence of poverty between the 2 survey years. About 81 percent of the male-headed households were multidimensionally poor as compared to 70 percent female-headed households and 89 percent of those living in the rural areas were poor as compared to 43 percent living in urban areas. MPI for the country stood at a higher level as compared to income poverty. Inequalities among the MPI's poor respondents showed variations for different groups. In 2011, the MPI inequalities were about 0.32 while these were 0.34 in 2014. MPI inequalities were higher for male-headed households and for those living in urban areas.

Table 11 presents the contribution of each attribute to multidimensional poverty. Housing facility, education, asset ownership, consumption expenditure, health, and energy use indices stand in their order of contribution to the multidimensional poverty index.

Dimensional contribution to multidimensional poverty provides more policy relevant information as it can single out the effect of each dimension on poverty. As can be seen in Table 11, the deprivation in health index had the highest share followed by the housing facility index and the energy use index. Any policy for poverty reduction and improving households' welfare can design and plan resources considering the severity of deprivations in each indicator.

\subsection{Determinants of Unidimensional and Multidimensional Poverty}

Examining the extent of poverty using both unidimensional and multidimensional measures conveys basic information on the degree of poverty in the study area. However, it does not tell us the factors which affect a household's poverty status. This research used a logit model for identifying the determinants of both unidimensional and multidimensional poverty. Before running the final regression, we conducted all diagnostic tests and confirmed the adequacy of our model. It passed all the relevant diagnostic tests. For examining the 
determinants of unidimensional poverty using consumption expenditure we added some variables which indicate asset ownership and room facilities. These variables are excluded from the determinants of the multidimensional poverty analysis as they are already accounted for in the computation of the index. However, the probable effects of their exclusion were tested and the model without these variables passed the misspecification test. Table 12 presents the regression results and their marginal effects.

The regression results in Table 12 show that household size had a non-linear effect on poverty. Poverty increased initially with an increase in household size and then decreased. This non-linear effect of household size can be attributed to scale effects in production and consumption. Economies of scale seem to be in operation in the latter family size. This result is similar to Deutsch and Silber's (2005) findings. A higher number of rooms occupied by a household, possession of one more unit of assets, and access to credit reduced the probability of a household being poor in the unidimensional case. A married household head had a lower probability of being poor as compared to other groups of marital status.

Similarly, a literate household head had a lower probability of being poor as compared to an illiterate household head. On the other hand, households living in rural areas had a higher probability of being poor as compared to those living in urban areas. The probability of households living in rural parts being multidimensionally poor was about 0.486 higher than for those living in small towns. The probability that a household with a literate head became multidimensionally poor was lower by about 0.399 as compared to a household with an illiterate head. This shows that education, though intrinsically a source of well-being is also instrumental in reducing poverty. Female-headed households had a lower probability of being poor as compared to male-headed households using consumption expenditure while they had a higher probability of being poor in the multidimensional indicator of poverty. Households living in various regions of the country had different probabilities of being poor. Most of the regional dummies indicate that households living in these regions had a higher probability of being poor as compared to households living in Dire Dawa (reference group) except those living in the Afar and Harari regions.

\section{Summary and Conclusion}

This research used 2 rounds of household survey data from rural and small towns in Ethiopia to analyze the extent and determinants of poverty. It explored both the conventional unidimensional method of poverty analysis and a multidimensional approach. In the conventional method, it used consumption expenditure and analyzed the poverty status of households. Because of the limitations surrounding traditional measures of poverty we also used multidimensional methods following Alkire and Foster (2007, 2011). Multiple correspondence analyses (MCA) were used for estimating the relative weights used for creating the multidimensional index of poverty. Similarly, the study conducted a stochastic dominance analysis of consumption expenditure for different groups and examined the extent of multidimensional inequalities using the Araar (2009) composite index. Finally, the logit model was estimated for examining the effects of determinants of poverty.

The results of our study show that a unidimensional approach understates the extent of poverty as it does not consider its non-monetary aspects. The unidimensional FGT poverty index shows that the incidence of poverty was about 36 percent whereas the multidimensional poverty index indicates that the incidence of poverty was about 80 percent. Dimension-wise multidimensional poverty carries important information for policy design 
Table 12 Determinants of poverty (Unidimensional and Multidimensional Poverty Index)

\begin{tabular}{|c|c|c|c|c|}
\hline \multirow{2}{*}{$\begin{array}{l}\text { Dependent variable } \\
\text { Variables }\end{array}$} & \multicolumn{2}{|c|}{ Unidimensional } & \multicolumn{2}{|c|}{ Multidimensional (MPI) } \\
\hline & Logit model & Marginal effects & Logit model & Marginal effects \\
\hline Household size & $\begin{array}{l}0.364 * * * \\
(0.046)\end{array}$ & $\begin{array}{l}0.088^{* * *} \\
(0.011)\end{array}$ & $\begin{array}{l}0.096 * * \\
(0.046)\end{array}$ & $\begin{array}{l}0.024 * * \\
(0.011)\end{array}$ \\
\hline Household size squared & $\begin{array}{l}-0.010 * * * \\
(0.004)\end{array}$ & $\begin{array}{l}-0.002 * * * \\
(0.001)\end{array}$ & $\begin{array}{l}-0.008^{* *} \\
(0.004)\end{array}$ & $\begin{array}{c}-0.002^{* *} \\
(0.001)\end{array}$ \\
\hline Age of household head & $\begin{array}{c}0.012 \\
(0.010)\end{array}$ & $\begin{array}{c}0.003 \\
(0.002)\end{array}$ & $\begin{array}{l}-0.013 \\
(0.011)\end{array}$ & $\begin{array}{r}-0.003 \\
(0.002)\end{array}$ \\
\hline Age of household head squared & $\begin{array}{r}-0.0001 \\
(0.0001)\end{array}$ & $\begin{array}{r}-0.00003 \\
(0.00002)\end{array}$ & $\begin{array}{l}0.0001 \\
(0.0001)\end{array}$ & $\begin{array}{c}0.00003 \\
(0.00003)\end{array}$ \\
\hline Head of household is female & $\begin{array}{r}-0.084 \\
(0.084)\end{array}$ & $\begin{array}{r}-0.020 \\
(0.020)\end{array}$ & $\begin{array}{l}0.300 * * * \\
(0.091)\end{array}$ & $\begin{array}{l}0.073 * * * \\
(0.022)\end{array}$ \\
\hline Household lives in a rural area & $\begin{array}{l}0.314 * * * \\
(0.090)\end{array}$ & $\begin{array}{l}0.073 * * * \\
(0.021)\end{array}$ & $\begin{array}{l}2.311 * * * \\
(0.106)\end{array}$ & $\begin{array}{l}0.486^{* * *} \\
(0.014)\end{array}$ \\
\hline Head of household is married & $\begin{array}{l}-0.380 * * * \\
(0.088)\end{array}$ & $\begin{array}{l}-0.093 * * * \\
(0.022)\end{array}$ & $\begin{array}{l}-0.344 * * * \\
(0.095)\end{array}$ & $\begin{array}{c}-0.083^{* * *} \\
(0.014)\end{array}$ \\
\hline Head of household is literate & $\begin{array}{l}-0.470 * * * \\
(0.058)\end{array}$ & $\begin{array}{l}-0.111 * * * \\
(0.014)\end{array}$ & $\begin{array}{l}-1.695^{* * *} \\
(0.060)\end{array}$ & $\begin{array}{c}-0.399 * * * \\
(0.013)\end{array}$ \\
\hline Household has access to credit & $\begin{array}{r}-0.026 \\
(0.058)\end{array}$ & $\begin{array}{r}-0.006 \\
(0.014)\end{array}$ & $\begin{array}{l}-0.038 \\
(0.063)\end{array}$ & $\begin{array}{r}-0.009 \\
(0.015)\end{array}$ \\
\hline Household lives in the Tigray region & $\begin{array}{l}0.351 * * \\
(0.167)\end{array}$ & $\begin{array}{l}0.086^{* *} \\
(0.042)\end{array}$ & $\begin{array}{l}0.392 * * \\
(0.165)\end{array}$ & $\begin{array}{l}0.094 * * \\
(0.038)\end{array}$ \\
\hline Household lives in the Afar region & $\begin{array}{r}-0.211 \\
(0.209)\end{array}$ & $\begin{array}{r}-0.050 \\
(0.047)\end{array}$ & $\begin{array}{l}0.770 * * * \\
(0.209)\end{array}$ & $\begin{array}{l}0.173 * * * \\
(0.041)\end{array}$ \\
\hline Household lives in the Amhara region & $\begin{array}{l}1.043^{* * *} \\
(0.158)\end{array}$ & $\begin{array}{l}0.255^{* * *} \\
(0.037)\end{array}$ & $\begin{array}{l}0.629 * * * \\
(0.154)\end{array}$ & $\begin{array}{l}0.149 * * * \\
(0.035)\end{array}$ \\
\hline Household lives in the Oromia region & $\begin{array}{c}0.253 \\
(0.159)\end{array}$ & $\begin{array}{c}0.062 \\
(0.039)\end{array}$ & $\begin{array}{l}0.374 * * \\
(0.154)\end{array}$ & $\begin{array}{l}0.090^{* *} \\
(0.036)\end{array}$ \\
\hline Household lives in the Somalie region & $\begin{array}{c}0.018 \\
(0.181)\end{array}$ & $\begin{array}{c}0.004 \\
(0.044)\end{array}$ & $\begin{array}{l}0.747 * * * \\
(0.178)\end{array}$ & $\begin{array}{l}0.170^{* * *} \\
(0.036)\end{array}$ \\
\hline $\begin{array}{l}\text { Household lives in Benshangul Gumuz } \\
\text { region }\end{array}$ & $\begin{array}{l}1.294^{* * *} \\
(0.196)\end{array}$ & $\begin{array}{l}0.309^{* * *} \\
(0.041)\end{array}$ & $\begin{array}{l}0.617 * * * \\
(0.204)\end{array}$ & $\begin{array}{l}0.142 * * * \\
(0.043)\end{array}$ \\
\hline Household lives in the SNNP region & $\begin{array}{l}0.753^{* * *} \\
(0.155)\end{array}$ & $\begin{array}{l}0.184 * * * \\
(0.038)\end{array}$ & $\begin{array}{l}0.984 * * * \\
(0.152)\end{array}$ & $\begin{array}{l}0.227 * * * \\
(0.032)\end{array}$ \\
\hline Household lives in the Gambelia region & $\begin{array}{l}0.753 * * * \\
(0.202)\end{array}$ & $\begin{array}{l}0.186^{* * *} \\
(0.049)\end{array}$ & $\begin{array}{l}0.584 * * * \\
(0.209)\end{array}$ & $\begin{array}{l}0.135^{* * * *} \\
(0.045)\end{array}$ \\
\hline Household lives in the Harari region & $\begin{array}{l}-0.695 * * * \\
(0.227)\end{array}$ & $\begin{array}{l}-0.152 * * * \\
(0.044)\end{array}$ & $\begin{array}{l}-1.079 * * * \\
(0.206)\end{array}$ & $\begin{array}{l}-0.260 * * * \\
(0.044)\end{array}$ \\
\hline Number of rooms & $\begin{array}{l}-0.208^{* * *} \\
(0.029)\end{array}$ & $\begin{array}{l}-0.050 * * * \\
(0.007)\end{array}$ & $\begin{array}{l}- \\
-\end{array}$ & - \\
\hline Number of assets & $\begin{array}{c}-0.195 * * * \\
(0.037)\end{array}$ & $\begin{array}{c}-0.047^{* * * *} \\
(0.01)\end{array}$ & $\begin{array}{l}- \\
-\end{array}$ & - \\
\hline Constant & $\begin{array}{c}-1.985^{* * *} \\
(0.307)\end{array}$ & & $\begin{array}{l}-1.416^{* * * *} \\
(0.312)\end{array}$ & \\
\hline
\end{tabular}

Reference group for the regional dummy is Dire Dawa; standard errors are in parenthesis; and ***, **, and * show significance at 1,5 , and $10 \%$ levels respectively 
and poverty targeting interventions. The results of our study show that the extent of multidimensional poverty was very high which requires concerted policy interventions. Besides, inequalities among the multidimensionally poor were about 0.33 with observable variations over time and across regions.

To combat this multifaceted, spatially diverse, and deep-rooted poverty in its different forms a one-size-fits-all policy may not produce impressive results. Policymakers should consider regional variations, community realities, and households' characteristics for fighting poverty. Expanding education and opportunities for production (access to credit) and pro-poor policy interventions will play significant roles in reducing poverty. National or global development targets should consider multidimensional poverty indicators for monitoring and reducing poverty in its many dimensions as post-2015 Sustainable Development Goals. As a further research area extending the indicators to capture missing dimensions of well-being, decomposition of inequalities using functional income distribution, and examining the extent of horizontal inequalities may address the knowledge gaps in this area.

\section{Appendix}

See Table 13.

Table 13 Nutrition (calorie)

based equivalence scales. Source: Dercon and Krishnan (1998) which was calculated using WHO data

\begin{tabular}{lll}
\hline Years of age & Men & Women \\
\hline $0-1$ & 0.33 & 0.33 \\
$1-2$ & 0.46 & 0.46 \\
$2-3$ & 0.54 & 0.54 \\
$3-5$ & 0.62 & 0.62 \\
$5-7$ & 0.74 & 0.70 \\
$7-10$ & 0.84 & 0.72 \\
$10-12$ & 0.88 & 0.78 \\
$12-14$ & 0.96 & 0.84 \\
$14-16$ & 1.06 & 0.86 \\
$16-18$ & 1.14 & 0.86 \\
$18-30$ & 1.04 & 0.80 \\
$30-60$ & 1.00 & 0.82 \\
$60-$ & 0.84 & 0.74 \\
\hline
\end{tabular}


Funding Open Access funding provided by Jönköping University.

Open Access This article is licensed under a Creative Commons Attribution 4.0 International License, which permits use, sharing, adaptation, distribution and reproduction in any medium or format, as long as you give appropriate credit to the original author(s) and the source, provide a link to the Creative Commons licence, and indicate if changes were made. The images or other third party material in this article are included in the article's Creative Commons licence, unless indicated otherwise in a credit line to the material. If material is not included in the article's Creative Commons licence and your intended use is not permitted by statutory regulation or exceeds the permitted use, you will need to obtain permission directly from the copyright holder. To view a copy of this licence, visit http://creativecommons.org/licenses/by/4.0/.

\section{References}

Achia, T. N., Wangombe, A., \& Khadioli, N. (2010). A logistic regression model to identify key determinants of poverty using demographic and health survey data. European Journal of Social Sciences, 3(1), $38-45$.

Alkire, S. (2007). Choosing dimensions: The capability approach and multidimensional poverty. SSRN Electronic Journal. https://doi.org/10.2139/ssrn.1646411.

Alkire, S. and Foster, J.E. (2007). Counting and Multidimensional Poverty Measurement. OPHI Working Paper No 7.

Alkire, S., \& Foster, J. E. (2011). Counting and multidimensional poverty measurement. Journal of Public Economics, 95, 476-487.

Alkire, S., \& Santos, M. E. (2010). Acute multidimensional poverty: A new index for developing countries. SSRN Electronic Journal. https://doi.org/10.2139/ssrn.1815243.

Alkire, S., \& Santos, M. E. (2014). Measuring acute poverty in the developing world: Robustness and scope of the multidimensional poverty index. World Development, 59, 251-274.

Ambel, A., Mehta, P. and Yigezu, B. (2015). Multidimensional poverty in Ethiopia: Changes in overlapping deprivations. Policy Research, World Bank, Working Paper No. 7417.

Anderson, G. (1996). Nonparametric tests of stochastic dominance in income distributions. Econometrica, 64(5), 1183-1193.

Anwar, T., \& Qureshi, S. (2002). Trends in absolute poverty in Pakistan: 1990-91 and 2001. The Pakistan Development Review, 41(4), 859-878.

Araar, A. (2009). The hybrid multidimensional index of inequality. SSRN Journal. https://doi.org/10.2139/ ssrn. 1496505.

Asselin, L. M. (2002). Composite indicator of multidimensional poverty, centre for international studies and cooperation (CECI). Canada: Montreal.

Atkinson, A. B. (1987). On the measurement of poverty. Econometrica, 55(4), 749-764.

Atkinson, A. B. (2003). Multidimensional deprivation: Contrasting social welfare and counting approaches. Journal of Economic Inequality, 1, 51-65.

Barrett, G., \& Donald, S. (2003). Consistent tests for stochastic dominance. Econometrica, 71(1), 71-104.

Berisso, O. (2016). Determinants of Consumption Expenditure and Poverty Dynamics in Urban Ethiopia: Evidence from Panel Data. In Almas Heshmati (ed.), Poverty and Well-being in East Africa: A Multifaceted Economic Approach, Chap. 7, pp. 138-164, Springer.

Bossert, W., Chakravarty, S., \& D’Ambrosio, C. (2013). Multidimensional poverty and material deprivation with discrete data. Review of Income and Wealth, 59, 29-43.

Bourguignon, F., \& Chakravarty, S. R. (2003). The measurement of multidimensional poverty. Journal of Economic Inequality, 1, 25-49.

Brück, T., \& Sindu, W. K. (2013). Dynamics and drivers of consumption and multidimensional poverty: Evidence from rural Ethiopia. SSRN Electronic Journal. https://doi.org/10.2139/ssrn.2248670.

Buhmann, B., Rainwater, L., Schmaus, G., \& Smeeding, T. M. (1988). Equivalence scales, well-being inequality, and poverty: Sensitivity estimates across ten countries using the luxembourg income study (LIS) database. Review of Income and Wealth, 34(2), 115-142.

Cameron, A. C., \& Trivedi, P. K. (2005). Microeconometrics: Methods and applications. New York: Cambridge University Press.

Chakravarty, S., \& D'Ambrosio, C. (2006). The measurement of social exclusion. Review of Income and Wealth, 52(3), 377-398. 
Chakravarty, S. R., Mukherjee, D., \& Ranade, R. R. (1998). On the family of subgroup and factor decomposable measures of multidimensional poverty. Research on Economic Inequality, 8, 175-194.

Coulter, F., Cowell, F., \& Jenkins, S. (1992). Equivalence scale relativities and the extent of inequality and poverty. The Economic Journal, 22(414), 1067-1082.

CSA and WB (2013) Living Standards Measurement Study-Integrated Surveys on Agriculture (LSMSISA): Ethiopia Rural Socioeconomic Survey (ERSS) Basic Information Document.

CSA and WB (2015). Living Standards Measurement Study- Integrated Surveys on Agriculture (LSMSISA): Ethiopia Rural Socioeconomic Survey (ERSS) Basic Information Document.

Davidson, R., \& Duclos, J. Y. (2000). Statistical inference for stochastic dominance and for the measurement of poverty and inequality. Econometrica, 68(6), 1435-1464.

Deaton, A. (2003). Household surveys, consumption, and the measurement of poverty. Economic Systems Research, 15(2), 135-159.

Deaton, A. (2005). Measuring poverty in a growing world (or measuring growth in a poor world). The Review of Economics and Statistics, 87(1), 1-19.

Deaton, A., \& Paxson, C. (1998). Economies of scale, household size, and the demand for food. The Journal of Political Economy, 106(5), 897-930.

Decancq, K., \& Lugo, M. A. (2013). Weights in multidimensional indices of wellbeing: An overview. Econometric Reviews, 32(1), 7-34.

Dercon, S., Hoddinott, J., \& Woldehanna, T. (2005). Shocks and consumption in 15 Ethiopian villages: 1999-2004. Journal of African Economies, 14(4), 559-585.

Dercon, S. and Krishnan, P. (1998). Changes in Poverty 1989-1995: Measurement, Robustness Tests and Decomposition. Centre for the Study of African Economies, Working Paper Series WPS98-7.

Dercon, S., \& Krishnan, P. (2000). Vulnerability, seasonality and poverty in Ethiopia. Journal of Development Studies, 36(6), 25-53.

Deutsch, J., \& Silber, J. (2005). Measuring multidimnsional poverty: An empirical comparison of various approaches. Review of Income and Wealth, 51(1), 145-174.

Duclos, J. Y., \& Araara, A. (2006). Poverty and equity: Measurement, policy and estimation with DAD. NewYork: Springer and International Development Research Centre.

FDRE. (2011). Country strategy paper 2011-2015. Ethiopia: Addis Ababa.

FDRE. (2016). Second five year growth and transformation plan (2016-2020). Addis Ababa, Ethiopia: National Plan Commision.

Foster, J., Greer, J., \& Thorbecke, E. (1984). A class of decomposable poverty measures. Econometrica, 52(3), 761-766.

Foster, J., Seth, S., Lokshin, M., \& Sajaia, Z. (2013). A unified approach to measuring poverty and inequality: Theory and practice. Washington, DC: The World Bank.

Foster, J. E., \& Shorrocks, A. F. (1991). Subgroup consistent poverty indices. Econometrica, 59(3), 687-709.

Glewwe, P. (1991). Household equivalence scales and the measurement of inequality: Transfers from the poor to the rich could decrease inequality. Journal of Public Economics, 44, 211-216.

Green, W. H. (2003). Econometrics analysis (5th ed.). New Jersey: Prentice Hall.

Gronau, R. (1988). Consumption technology and the intra-family distribution of resources: Adult equivalence scales reexamined. Journal of Political Economy, 98(6), 1183-1205.

Gustafsson, B. (1995). Assessing poverty: Some reflections on the literature. Journal of Population Economics, 8(4), 362-382.

Hagenaars, A. (1987). A class of poverty indices. International Economic Review, 28(3), 583-607.

Hagenaars, A., \& De Vos, K. (1988). The definition and measurement of poverty. The Journal of Human Resources, 23(2), 211-221.

HDR. (2013). The rise of the south: Human progress in a diverse world. New York: United Nations Development Programme.

HDR. (2014). Sustaining human progress: Reducing vulnerabilities and building resilience. New York: United Nations Development Programme.

HDR. (2015). Work for human development. New York: United Nations Development Programme.

Housseima, G., \& Jaleleddine, B. R. (2012). Multidimensional poverty in Tunisia: A non-monetary approach applied to east-central Tunisia. Interdisciplinary Journal of Contemporary Research in Business, 3(9), 856-876.

Kakwani, N. (1993). Statistical inference in the measurement of poverty. The Review of Economics and Statistics, 75(4), 632-639.

Kakwani, N., \& Silver, J. (2008). Introduction: Multidimensional poverty analysis: Conceptual issues, empirical illustrations and policy implications. World Development, 36(6), 987-991. 
Khan, A. U., Saboor, A., Hussain, A., Sadiq, S., \& Mohsin, A. Q. (2014). Poverty assessment as a multidimensional socio-economic concept: The case of the Rawalpindi region in Pakistan. Asia Pacific Journal of Social Work and Development, 24(4), 238-250.

Kim, S. G. (2015). Fuzzy multidimensional poverty measurement: An analysis of statistical behaviors. Social Indicators Resserach, 120, 635-667.

Krzanowski, W. J. (1987). Cross-validation in principal component analysis. Biometrics, 43(3), 575-584.

Maasoumi, E. (1986). The measurement and decomposition of multi-dimensional inequality. Econometrica, 54(4), 991-998.

Maasoumi, E., \& Heshmati, A. (2000). Stochastic dominance amongst swedish income distribution. Econometric Reviews, 19(3), 287-320.

Maasoumi, E., \& Heshmati, A. (2008). Evaluating dominance ranking of PSID incomes by various household attributes. London and New York: Routledge.

Maasoumi, E., \& Xu, T. (2015). Weights and substitution degree in multidimensional well-being in China. Journal of Economic Studies, 42(1), 4-19.

MoFED. (2008). Dynamics of growth and poverty in Ethiopia (1995/96-2004/05). Addis Ababa, Ethiopia: Development planning and research department, ministry of finance and economic development.

Muller, C. (2006). Defining poverty lines as a fraction of central tendency. Southern Economic Journal, 72(3), 720-729.

Nussbaum, M. (2003). Capabilities as fundamental entitlements: Sen and social justice. Feminist Economics, 9, 33-59.

Rao, C. R. (1964). The use and interpretation of principal component analysis in applied research Sankhyā. The Indian Journal of Statistics, 26(4), 329-358.

Ravallion, M. (1994). Measuring social welfare with and without poverty lines. The American Economic Review, 84(2), 359-364.

Ravallion, M. (1996). Issues in measuring and modelling poverty. The Economic Journal, 106(438), 1328-1343.

Ravallion, M. (2011). On multidimensional indices of poverty. Journal of Economic Inequality, 9(2), $235-248$.

Ravallion, M., \& Huppi, M. (1991). Measuring changes in poverty: A methodological case study of Indonesia during an adjustment period. The World Bank Economic Review, 5(1), 57-82.

Ray, R. (2000). Poverty, household size and child welfare in India. Economic and Political Weekly, 35(39), 3511-3520.

Rippin, N. (2010) Poverty severity in a multidimensional framework: the issue of inequality between dimensions. Courant Research Center, Discussion Paper No. 47, University of Göttingen.

Rogan, M. (2016). Gender and multidimensional poverty in South Africa: Applying the global multidimensional poverty index (MPI). Social Indicator Research, 126, 987-1006.

Ruiz-Castillo, J. (2015). The measurement of the inequality of opportunities. In Y. Amiel \& J. A. Bishop (Eds.), Inequality, welfare and poverty: Theory and measurement, 9 (pp. 1-34). Bingley: Emerald Group Publishing Limited.

Sen, A. (1976). Poverty: An ordinary approach to measurement. Econometrica, 44(2), 219-231.

Sen, A. (1979). Issues in the measurement of poverty. The Scandinavian Journal of Economics, 81(2), 285-307.

Sen, A. (1985). Commodities and capabilities. Amsterdam: North-Holland.

Sen, A. (1990). Development as capability Expansion. Cambridge: Harvard University.

Sen, A. (1999). Development as freedom. Oxford: Oxford University Press.

Shorrocks, A. F. (1995). Revisiting the sen poverty index. Econometrica, 63(5), 1225-1230.

Townsend, P. (1970). The concept of poverty. London: Hienemann.

Tsui, K. (1999). Multidimensional inequality and multidimensional generalized entropy measures: An axiomatic derivation. Social Choice and Welfare, 16, 145-157.

Tsui, K. (2002). Multidimensional poverty indices. Social Choice and Welfare, 19, 69-93.

Whelan, C. T., Nolan, B., \& Maître, B. (2014). Multidimensional poverty measurement in Europe: An application of the adjusted headcount approach. Journal of European Social Policy, 24(2), 183-197.

WHO. (2002). Addressing the links between indoor air pollution, household energy and human health. Washington, DC: World Health Organization.

WHO. (2007). Indoor air pollution: National burden of disease estimates. France: WHO.

Woldehanna, T. (2014). Measuring Multidimensional Poverty: Capabilities, Deprivation, and Social Exclusion in Rural and Urban Ethiopia. CSAE working paper series.

Zimmermann, H. J. (2010). Fuzzy Set Theory. Advanced Review, 2, 317-332.

Publisher's Note Springer Nature remains neutral with regard to jurisdictional claims in published maps and institutional affiliations. 